\title{
Consumer responses to corporate social irresponsibility: The role of moral emotions, evaluations, and social cognitions
}

\author{
Chunyan $\mathrm{Xie}^{1}{ }^{1}$ | Richard P. Bagozzi ${ }^{2}$
}

${ }^{1}$ Department of Business Administration, Faculty of Business Administration and Social Sciences, Western Norway University of Applied Sciences, Bergen, Norway

${ }^{2}$ Ross School of Business, University of Michigan, Ann Arbor, Michigan

\section{Correspondence}

Richard P. Bagozzi, University of Michigan, 701 Tappan St., Ann Arbor, MI 48109-1234. Email: bagozzi@umich.edu

\section{Funding information}

Norges Forskningsråd, Grant/Award Number: 192270; The Research Council of Norway

\begin{abstract}
We investigate the mediating roles of moral emotions and attitudes between perceptions of corporate irresponsible actions, on the one hand, and consumer responses, on the other hand, and further examine their contingencies based on consumer social cognitions. Our findings show that, for corporate transgressions, multiple social cognitions (moral identity, relational and collective self-concepts, and affective empathy) moderate the elicitation of negative moral emotions (contempt and anger) and overall evaluations (attitudes), which, in turn, lead to negative responses toward the company (negative word of mouth, complaint behaviors, and boycotting). Our study adds to extant research on corporate social irresponsibility by examining three generic reactions people have toward corporate social irresponsibility and demonstrating important boundary conditions. In addition, hypotheses are tested on a sample of adult consumers. Implications for communication by firms are considered.
\end{abstract}

KEYWORDS

attitudes, contempt, corporate social irresponsibility, moral emotions, righteous anger, social cognitions

\section{1 | INTRODUCTION}

Corporate social responsibility (CSR) is an important topic in modern business life with wide ramifications for companies, consumers, and other stakeholders. CSR is defined as "an organization's status and activities with respect to its perceived societal obligations" (Brown \& Dacin, 1997, p. 6). On the one hand, not only are companies devoting increased effort to their CSR initiatives, but also the public and consumers are paying more and more attention toward companies' CSR actions in their decision making and adoption practices (Peloza \& Shang, 2011). On the other hand, less attention has been given to corporate social irresponsibility (CSI), but a number of studies have been conducted in recent years (Antonetti \& Maklan, 2016a; Grappi, Romani, \& Bagozzi, 2013a; Vaaland, Heide, \& Grønhaug, 2008). Consumers are getting more sensitive to CSI and expressing stronger reactions toward CSI, which often lead to serious consequences for offending companies. Understanding how consumers respond to CSI incidents is crucial for the survival and prosperity of companies. Therefore, a better understanding of consumer responses toward CSI and its underlying psychological mechanisms is in great need. The current study attempts to address this issue by exploring psychological mechanisms underlying consumer reactions toward company CSI actions.

\section{1 | Three generic reactions toward CSI}

When people are exposed to corporate irresponsible actions, how do they interpret, make sense of, and respond to such actions? Research suggests that their reactions often happen in an intuitive way (Haidt, 2012; Weaver, Reynolds, \& Brown, 2014), either through spontaneous emotional or evaluative responses or through social cognitions. That is, CSR actions constitute events interpreted by consumers through learned or generalized psychological reactions.

The first generic reactions are automatic emotional reactions proposed by Haidt and his colleagues in the intuitionist approach to moral behavior (Haidt, 2012; Rozin, Lowery, Imada, \& Haidt, 1999). We propose that bad corporate practices evoke negative moral 
emotions in consumers, and such feelings are in a sense informational to the person experiencing them and others observing them. For instance, contempt, anger, and disgust have been studied as automatic emotional responses toward CSI actions in previous studies of consumers (e.g., Grappi et al., 2013a; Xie, Bagozzi, \& Grønhaug, 2015).

The second generic reactions are automatic evaluative responses, which are good-bad reactions and come out of the attitude tradition (e.g., Ajzen \& Fishbein, 1980; Judge \& Kammeyer-Mueller, 2012). To evaluate something means to consider whether it is good or bad, favorable or unfavorable, positive or negative, or some similar appraisal of the evaluative significance of the event one experiences for the self. Although evaluations can be deliberative, they are often automatic or reactive, such as occurs with learned behavior. Such overall evaluative reactions are often positively correlated with emotional reactions but are distinct from emotions in content, internal representation, and processes. Herein we define attitude as an overall evaluation of the company triggered by awareness of its CSI actions. Both overall emotional reactions (i.e., moral emotions) and overall evaluative responses (i.e., attitudes) by consumers are proposed to mediate the impact of perceived CSI actions on consumer behavioral responses toward the company.

The third generic reactions are social cognitive responses that have to do with things consumers learn in thoughtful ways concerning their relationships with other people or institutions and how they interpret or make sense of these experiences. People learn and develop social cognitions through previous experiences in psychological development and socialization processes or as members of groups or organizations. For instance, consumers might interpret corporate irresponsible actions through a moral lens, through felt group aspects of selves, or through empathy toward others' sufferings. People possess such social cognitions to different degrees, and thus social cognitions are individual difference variables. We suggest that social cognitions moderate and condition overall emotional and evaluative reactions toward perceived CSI incidents. Social cognitions may limit or expand emotions and evaluations in response to CSI actions. By doing so, they transform overall emotional and evaluative reactions into forces to induce actions by consumers in relation to a company.

In sum, we propose that consumers respond in three ways to CSI actions: emotionally, evaluatively, and cognitively in a social sense. Emotional and evaluative responses function to answer the question of how people react to CSI actions. Emotional and evaluative reactions do this by mediating the influence of perceived CSI actions on decisions regarding how to act toward companies committing CSI acts. Social cognitions answer the question when people react to corporate actions. They do this by moderating the influence of perceived CSI actions and thereby specifying boundary conditions the elicitation of emotional and evaluative reactions.

\section{2 | A brief review of previous research on CSI}

Previous research on CSI in the field of marketing has taken mostly a managerial approach and considered firm-oriented and rational criteria. For instance, Folkes and Kamins (1999) find that company CSI actions lead to negative attitudes toward the company. Elsbach and Bhattacharya (2001) show that CSI action leads to consumer disidentification with the firm. Vaaland et al. (2008) review 54 articles on CSR and CSI in the field of marketing and find that CSI actions generally influence consumer company evaluations and lead to consumer negative attitudes toward the firm.

Recently, Haidt $(2003,2012)$ criticized the dominance of cognitive approaches in moral judgment and proposed a social intuitionist model claiming that people use moral intuitions (especially moral emotions) as a foundational basis for their moral judgments. Some recent studies have applied Haidt's emotional approach to study CSI. For instance, negative moral emotions have been examined as mediators, channeling the effect of perceptions of company CSI actions on consumer responses (e.g., Antonetti \& Maklan, 2016a, 2017; Grappi et al., 2013a; Xie et al., 2015). Some of those studies investigate only the mediating role of moral emotions (Antonetti \& Maklan, 2016a, 2017), whereas others further explore moderators of the mediating processes (Grappi et al., 2013a; Xie et al., 2015).

Both the cognitive and emotional approaches to date have focused primarily on one type of mediation process between perceptions of $\mathrm{CSI}$ and consumer responses. However, we propose that two distinct mediational processes are important to investigate for understanding the psychological mechanisms underlying consumer decisions toward CSI. To position our approach within the landscape of the emerging literature on CSI, especially among recent studies taking an emotional approach, we briefly review these studies below before elaborating on our more comprehensive approach.

We use two classifying criteria to group these studies. The first criterion is whether the study addresses possible moderators of the emotional processes between CSI and consumer responses. The study of moderators is intended to uncover the conditions under which perceptions of CSI acts lead to consumer reactions. We further distinguish between the single moderator and multiple moderators, as shown in Table 1. The second criterion concerns the types of CSI actions studied. We adopt a framework of three ethic codes developed in anthropology (Shweder, Much, Mahapatra, \& Park, 1997) to classify the type of CSI actions: the ethics of divinity, community, and autonomy. Although Shweder et al.'s three ethics of morality were originally developed to interpret moral issues faced by individuals; we suggest that they can be extended more broadly to interpret diverse company CSI activities. That is, we can group CSI actions by considering how each group of actions violates one of the three basic ethics.

More specifically, violation of the ethics of divinity transpires when a person causes impurity or degradation of himself/herself, other persons, or objects (Rozin et al. 1999,), which can also be extended to degradation of the natural environment. Violation of the ethics of the community happens when "a person fails to carry out his or her duties within a community, or to the social hierarchy within the community" (Rozin et al., 1999, p. 575). Finally, violation of the ethics of autonomy occurs when an action "directly hurts another or 
TABLE 1 An overview of corporate social irresponsibility research applying the emotional approach and variants thereof

\begin{tabular}{|c|c|c|c|}
\hline Ethic codes & No moderator & Single moderator & Multiple moderators \\
\hline The ethics of divinity & $\begin{array}{l}\text { Antonetti (2016), Antonetti and Maklan } \\
\text { (2016a, 2017) }\end{array}$ & Antonetti and Maklan (2018) & Xie et al. (2015) \\
\hline The ethics of community & None & $\begin{array}{l}\text { Grappi et al. (2013a, 2013b), Romani } \\
\text { et al. (2015) }\end{array}$ & None. The current study \\
\hline
\end{tabular}

infringes upon his/her rights or freedoms as an individual" (Rozin et al., 1999, pp. 575-576).

As shown in Table 1, the left column summarizes studies to date that have only focused on the mediating processes of emotions and have not addressed possible boundary conditions qualifying their effects. For instance, Romani, Grappi, and Bagozzi, (2013a) investigate the mediating role of anger (contempt) between CSI actions and consumer constructive (destructive) punitive actions toward the offending company. They studied two types of CSI actions that violate the ethics of divinity and autonomy. Antonetti and Maklan (2016a, 2017) addressed how anger channels the impact of CSI actions on consumer intentions to punish the company. The CSI actions they study can be considered violations of the ethics of divinity (i.e., chemical spills in a water basin). Antonetti and Maklan (2016b) investigated the mediating role of moral outrage between perceived fairness of firm actions on negative word of mouth (NWOM). The irresponsible actions they studied are the firm unlawful promotion of products and tax avoidance practices that violate the ethics of autonomy. Further, Antonetti (2016) provides a conceptual model for consumer anger against a company based on its CSI actions. He includes two types of anger with different relational consequences: Vengeful anger leads to a desire to hurt the culprit and problem-focused anger leads to the attainment of a thwarted goal. In sum, the studies shown in column 1 of Table 1 address CSI actions violating the ethics of divinity and are limited to investigation only of mediating mechanisms; two studies in column 1 examined the ethics of autonomy, again limited to mediational mechanisms.

The middle column in Table 1 presents studies that explore only a single moderators of emotional mediators. Grappi et al. (2013a) found that CAD emotions (contempt, anger, and disgust) mediate the impact of $\mathrm{CSI}$ actions on consumer negative reactions toward the company. Consumer other-regarding virtues moderated the mediating processes. They studied two types of CSI actions that violate the ethics of autonomy and community. Grappi, Romani, and Bagozzi (2013b) investigated the mediating role of anger between company offshoring practices and consumer reactions toward the company. Consumer perceived risk of offshoring moderated the linkage between CSI actions and elicitation of moral emotions. Offshoring practices violate the ethics of the community. Romani, Grappi, Zarantonello, and Bagozzi (2015) found that consumer hate mediates the impact of brands and their parent companies' moral misconduct on consumer antibrand behavior. Consumer empathy moderated the effects of hateful feelings on antibrand behaviors. Antonetti and
Maklan (2018) examined the moderating role of collective national narcissism on the effect of national identity on the perceived similarity of victims in the context of the ethics of divinity. They also examined the moderating role of perceived severity of violations on the effects of the perceived similarity of victims on the sympathy of victims in the context of ethics of divinity, see Table 1.

Finally, the right-most column in Table 1 shows studies that have addressed multiple moderators of the emotional processes. Only one study (Xie et al., 2015) addressed multiple moderators of the mediating processes of moral emotions. Five different individual difference variables were investigated that moderate the elicitation of negative moral emotions CAD, which further lead to consumer negative reactions toward the company. This study investigates CSI actions under the ethics of divinity.

\section{3 | Contributions of the current study}

Based on Table 1, we can see two gaps in previous research applying an emotional approach to CSI: One gap is the need for more studies investigating multiple moderators of the emotional processes to provide fuller explanations of boundary conditions. A second gap is a need for more research addressing CSI actions that violate the ethics of autonomy and community, which have been understudied to date. Moreover, a third gap in the CSR research has been mentioned earlier: The need to consider both cognitive and emotional processes underlying consumer responses toward CSI. Our study investigates both cognitive and emotional mediation processes between perceptions of company CSI actions and consumer decisions and responses toward the company in a CSR setting that violates the ethics of community and autonomy. Furthermore, we explore multiple regulators of both processes. Our conceptual model is shown in Figure 1.

Our study makes several broad contributions. First, we consider when perceptions of CSI elicit moral emotions and attitudes. We do this by specifying and testing the regulatory effects of four moderators: moral identity, empathy, relational self-orientation, and collective self-orientation. Further, we test our conceptual model empirically in two specific settings where CSI actions happen: violations of the ethics of community and the ethics of autonomy. Second, our study adds to CSR research by incorporating both cognitive and emotional mediators between perceptions of CSI actions and consumer reactions toward the company. Previous research has focused on either cognitive or emotional processes. Our 


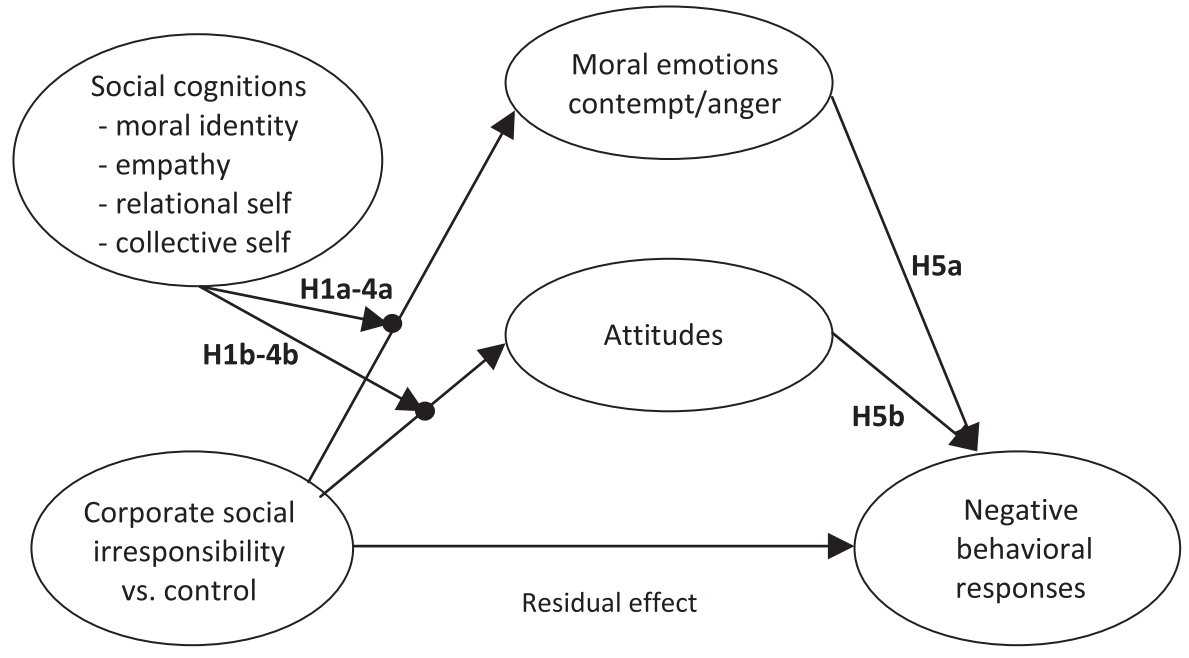

FIGURE 1 Conceptual model and hypotheses. Negative behavioral responses include NWOM, complaining, boycott 1 , boycott 2; see text for the full description (Section 3). NWOM: negative word of mouth

model deepens and broadens existing approaches to moral decision making. Although Dedeke (2015) has proposed a conceptual model including both cognitive and emotional processes in moral decision making, he did not develop specific hypotheses, and his approach has not been tested. Our study differs from his approach as well by treating emotions and attitudes as independent, parallel mediators thereby allowing us to test for the effects of each while controlling for the other. Finally, our study further explores possible regulating mechanisms of both cognitive and emotional processes between CSI and consumer reactions, which has not been done before (cf., Dedeke, 2015; Haidt, 2012).

The rest of the paper is organized as follows. We first develop the theoretical background and elaborate on our conceptual model as shown in Figure 1. Specific hypotheses are developed on how moral emotions and evaluations mediate the effects of perception of CSI actions on consumer responses and how social cognitions moderate such meditation processes. Then, we describe the research method, followed by a presentation of our empirical results. Finally, the contributions and implications of our research are discussed.

\section{2 | THEORETICAL BACKGROUND}

This section is organized around (a) the evocation of emotional and evaluative reactions by CSI, (b) theoretical arguments for moderating effects by consumer social cognitions on the elicitation of emotional and evaluative reactions ( $\mathrm{H} 1 \mathrm{a}-4 \mathrm{a}$ and $\mathrm{H} 1 \mathrm{~b}-4 \mathrm{~b})$, and (c) the effects of moral emotions and evaluations on behavioral responses of consumers toward the company ( $\mathrm{H} 5 \mathrm{a}$ and $\mathrm{H} 5 \mathrm{~b}$ ).

\section{1 | Corporate irresponsible actions and emotional and evaluative reactions}

Previous research shows that corporate social and ethical transgressions (Grappi et al., 2013a) and corporate irresponsible actions toward the environment (Xie et al., 2015) evoke negative emotions of contempt, anger, and disgust in consumers. Analogously, we argue that company actions that violate the ethics of community and autonomy provoke negative moral emotions.

More specifically, in our context of the study of the ethics of community, we argue that firm transgressions (e.g., rejecting local business contracts arbitrarily, building commercial docking facilities for the firm's benefit at popular recreational areas at the local citizens' expense, failing to make contributions to local clubs and sport teams, and refusing to participate in joint research and development initiatives) provoke the negative moral emotion of contempt. Such actions violate the ethics of the community because the firm fails to carry out its duties and obligations within the community it functions (Shweder et al., 1997).

Previous research into the effects of community violations shows that, in deciding whether an action is wrong or not, people "think about things like duty, role obligation, respect for authority, loyalty, group honor, interdependence, and the preservation of the community"; an action is judged wrong when one fails to carry out his or her duties within a community or with respect to the social hierarchy within the community (Rozin et al., 1999; pp. 575-576). Herein we study a firm's transgressions, which fail to fulfill the firm's duty and obligation toward its local community, such as supporting local business partners, respecting the rights and benefits of other members in the same community, and contributing to the development and preservation of the community. Clearly, such actions violate the ethical code of community, which elicits the negative moral emotion of contempt in people who perceive such CSI incidences. Contempt is often connected to hierarchy and a vertical dimension of social evaluation, and usually is manifest as a negative appraisal of others and their actions. According to Izard (1977), contempt is often felt by members of one group toward members of other groups regarded as inferior. Similarly, Ekman (1994) views contempt as disapproving and feeling morally superior to someone. Miller (1997) argues that contempt stems from the perception that another person does not measure up to either the position he/ she holds or the level of prestige he/she claims. Rozin et al. (1999) propose that violations of community codes will trigger contempt because contempt is often linked to hierarchical relations between individuals and groups. Accordingly, we argue that the corporate 
community transgressions described above will elicit contempt in consumers.

Next, in the context of the ethics of autonomy, we suggest that a firm's transgressions (e.g., trading with governments and companies viewed as unethical, failing to provide satisfactory working and safety conditions for its employees) induce the negative moral emotion of anger. Whether an action violates the ethics of autonomy depends on the extent to which it "directly hurts another or infringes upon his/her rights or freedoms as an individual" (Rozin et al., 1999, pp. 575-576). Abovementioned corporate actions violate the ethics of autonomy because the firm infringes on the rights or freedom of its employees and other people affected by unethical governments and companies (Shweder et al., 1997). Rozin et al. (1999) argue that anger will often be triggered by violations of autonomy codes as the appraisal condition for anger is often said to be an insult or rights violations. Therefore, righteous anger is the appropriate response to such injuries to people whom one sees as victimized.

Finally, previous studies show that corporate CSR transgressions lead to negative evaluations of companies (Folkes \& Kamins, 1999; Klein \& Dawar, 2004; Mohr \& Webb, 2005). For example, Folkes and Kamins (1999) find that corporate unethical labor practices elicit negative attitudes toward firms. Accordingly, we argue that corporate community irresponsibility and unethical business practices trigger negative evaluations by people, as shown in Figure 1. Herein we define attitudes as overall evaluations of the company. The intuitionist approach (e.g., Haidt, 2012) does not consider evaluative processes but rather focuses only on emotional reactions. However, we suggest that people express distinct evaluative and emotional reactions toward corporate CSR actions. By including both emotions and attitudes as parallel mediators, we provide a tougher test of each than has been done in the past. That is, the effects of each are tested, holding constant the effects of the other. We now discuss how affective and evaluative reactions are regulated by social cognitions.

\subsection{The moderating role of social cognitions}

Social cognitions are learned mental structures that regulate responses to cues from external events. In our case, these events are the awareness of CSI actions. Such corporate actions either violate the welfare of the community or disconfirm ethical expectations. They are interpreted through existing cognitive structures in people that are relevant for moral aspects of the self and interface with corresponding emotions and evaluations. Below, we introduce four social cognitions (i.e., moral identity, empathy, relational and collective self-concept) derived from our analysis of the ethical and emotional literature, and we develop how these regulate emotional and evaluative reactions (see Figure 1). These four social cognitions are chosen because of their compatibility with the CSR context. We choose moral identity because it captures the moral aspect of selfidentity, which matches the moral judgment processes trigged by a perception of CSI actions. Empathy is chosen due to its otherorientation focus (Xie, Bagozzi, \& Grønhaug, 2019). Empathy contains an element of caring and fits the CSR context studied herein. Relational and collective self-orientations are chosen because they capture the social aspects of the self-concept. A relational selfconcept has an other-focus (Markus \& Kitayama, 1991), in an interpersonal sense which is relevant to the CSR context. A collective self-concept is a group-based concept and fits the CSR context, especially the community ethics studied herein.

\subsection{1 | Moral identity}

We begin with the self-regulatory role of moral identity. Moral identity is the ethical content of one's self-identity. Aquino, Freeman, Reed, Lim, and Felps (2009) define it as the cognitive schema a person holds about his or her moral character, which comprises "a complex knowledge structure consisting of moral values, goals, traits, and behavioral scripts" that are "acquired through life experiences that vary across persons" (p. 124). This is consistent with our conceptualization of moral identity as social cognition. Moral identity is a powerful source of moral motivation due to the basic human desire to maintain self-consistency (e.g., Blasi, 2004). Aquino, McFerran, and Laven (2011) claim that moral identity affects the extent to which people assign psychological weight, relevance, and values to actions of uncommon moral goodness and therefore can enhance elicitation of the positive emotion of elevation. Another empirical study showed that moral identity moderated the degree people experience negative moral emotions upon awareness of corporate nongreen actions (Xie et al., 2015). Similarly, we argue that consumers with more central moral identity will assign higher weight and stronger relevance to corporate transgressions and are thus more likely to experience negative moral emotions than those with less central moral identity upon perceived company CSI actions.

Moreover, Aquino et al. (2009) show that the centrality of moral identity determines the likelihood of its activation within the working self-concept, thus influencing information processing. Therefore, we suggest that the more central people's moral identity, the more likely their moral identities will be activated and have a greater potential to influence information processing, and the more likely they will have negative evaluations toward the company CSI actions.

In total, we argue that the more central consumers' moral identities, the greater will be the impact of perceived CSI actions on emotional and evaluative reactions. Thus, we hypothesize a moderating effect of moral identity on elicitation of negative moral emotions ( $\mathrm{H} 1 \mathrm{a})$ and negative attitudes ( $\mathrm{H} 1 \mathrm{~b})$.

H1a: Upon perception of corporate community transgressions (corporate unethical business practices), those with more central moral identities are more likely to experience contempt (anger) than those with less central moral identities.

H1b: Upon perception of corporate community transgressions (corporate unethical business practices), those with more central moral identities are more likely to have more negative attitudes toward the company than those with less central moral identities. 


\subsection{2 | Empathy}

Empathy has been defined broadly as the ability to share another's emotions (Lazarus, 1991), and has at least two dimensions: cognitive and affective empathy (Lazarus, 1991; Losoya \& Eisenberg, 2001). We focus on affective empathy herein, which refers to a vicarious emotional response to another person and entails concern or compassion for another (Lazarus 1991, p. 288). Empathy is believed to contain both genetic and learned origins. It also varies across individuals and is thus an individual difference variable. As Tangney, Stuewig, and Mashek (2007) claim, "empathic reactions to others' distress often elicit feelings of concern for the distressed other" (p. 18). Empathic people are more likely to care about other people in distress. Romani et al. (2015) found that empathy moderates the effects of company moral misconduct on the negative feeling of hate because of the misalignment between moral violations with the other orientation of empathy. In the current study, we argue that the greater people's affective empathy, the more likely they will feel distressed and suffering of other people caused by CSI actions. We expect that affective empathy will enhance the evocation of moral emotions and attitudes when people learn about corporate irresponsibility. In other words, people with greater empathy are more sensitive to and more sympathetic toward the perception of CSI actions, and thus empathy moderates the degree of felt negative moral emotions and negative attitudes toward the company. Thus:

H2a: Upon perception of corporate community transgressions (corporate unethical business practices), those with greater empathetic concern are more likely to experience contempt (anger) than those with less empathetic concern.

H2b: Upon perception of corporate community transgressions (corporate unethical business practices), those with greater empathetic concern are more likely to have more negative attitudes toward the company than those with less empathetic concern.

\subsection{3 | Social self-concept}

Recent research distinguishes two levels of one's social self, the relational self-concept and the collective self-concept (Brewer \& Gardner, 1996; Johnson, Selenta, \& Lord, 2006). The relational self-concept refers to the extent people define themselves through dyadic or interpersonal relationships, and the collective self-concept refers to the degree people define themselves in terms of their social group memberships (Johnson et al., 2006). Both aspects of the self-concept develop socially and culturally through psychological development and the socialization processes. Both are learned social cognitions.

The self-concept at the relational level concerns the welfare of specific others and appropriate role behavior (Brewer \& Gardner, 1996). People with strong relational self-concepts have a heightened capacity to experience and express other-focused emotions (Markus \& Kitayama, 1991). The emotions of contempt and righteous anger studied herein are other-focused moral emotions. Therefore, consumers with stronger relational self-concepts will be more likely to experience other-focused moral emotions than those who are weaker in relational self-concepts. For instance, in our study corporate community transgressions portray exactly how the firm violates its role obligations in the community. We argue that such bad role behaviors are likely to interact with people's relational self-concepts that focus on the relationship between themselves and the community.

Markus and Kitayama (1991) also argue that people with strong relational selves will be more attentive and sensitive to others than those with weak relational selves, which results in relatively greater cognitive elaboration of the other. In the current study, we argue that consumers with stronger relational self-concepts will be more attentive and sensitive to both offender and sufferers of CSI incidences, and consequently more likely to elaborate more on their evaluations of the company which is negative.

To sum up, we propose that relational self-concepts influence the intensity that perceptions of bad corporate actions have on moral emotions and evaluations, as proposed in $\mathrm{H} 3 \mathrm{a}$ and $\mathrm{H} 3 \mathrm{~b}$.

H3a: Upon perception of corporate community transgressions (corporate unethical business practices), those with stronger relational selfconcepts are more likely to experience contempt (anger) than those with weaker relational self-concepts.

H3a: Upon perception of corporate community transgressions (corporate unethical business practices), those with stronger relational selfconcepts are more likely to have more negative attitudes toward the company than those with weaker relational self-concepts.

The collective self-concept focuses on the welfare of the groups to which one belongs (Brewer \& Gardner, 1996). Corporate irresponsible actions hurt the community directly and thus have an indirect impact on persons who are part of the community. Such corporate actions are likely to elicit both emotional and evaluative reactions to corporate community transgressions, to the degree that people hold collective selfconcepts. Under corporate unethical business practices, we also expect that consumers with strong collective self-concepts are more likely to recognize that such actions disregard or violate the ethical standard shared by the broad business community, and thus are more likely to have stronger evaluative and emotional reactions toward the offending company than those with weaker collective selves. Therefore, the moderating effects of the collective self-concept on elicitation of moral emotions and attitudes are proposed in $\mathrm{H} 4 \mathrm{a}$ and $\mathrm{H} 4 \mathrm{~b}$ :

H4a: Upon perception of corporate community transgressions (corporate unethical business practices), those with stronger collective selfconcepts are more likely to experience contempt (anger) than those with weaker collective self-concepts.

$\mathrm{H} 4 \mathrm{a}$ : Upon perception of corporate community transgressions (corporate unethical business practices), those with stronger collective selfconcepts are more likely to have more negative attitudes toward the company than those with weaker collective self-concepts. 


\subsection{The impact of moral emotions and attitudes on consumer responses}

Emotional and evaluative reactions by people toward corporate CSI actions motivate behavior to combat the negative practices. Once a person feels and experiences negative emotions, there is a need to cope with his/her discomfort by doing something about it. Negative emotions are typically tied to action tendencies that function as coping responses. Action tendencies for contempt are rejection and avoidance of contact with the offender and those for anger are attacking the offender (Lazarus, 1991). Negative emotions such as contempt and anger tend to narrow and focus a person's intention to punish the offender or make the offender change their specific offensive behaviors by stopping or reducing the negative actions (Fredrickson, 1998; Fredrickson \& Branigan, 2005). Therefore, in our study, we argue that contempt and righteous anger, caused by corporate community transgressions or unethical business practices, respectively, will lead specifically to the following negative responses toward the company: NWOM, complaint, and boycott behaviors, as suggested in $\mathrm{H} 5 \mathrm{a}$.

Moreover, according to theories of the attitude-behavior relationship, such as the theory of reasoned action (Ajzen \& Fishbein, 1980) the theory of planned behavior (Ajzen, 1991), and the theory of trying (Bagozzi \& Warshaw, 1990), attitudes are direct antecedents of behavioral intentions. Therefore, we propose that consumers' negative attitudes toward the company will lead to their intentions to engage in negative acts toward the company, as shown in $\mathrm{H} 5 \mathrm{~b}$.

H5a: The stronger the felt contempt (anger), the greater the consumer negative responses toward the company.

$\mathrm{H} 5 \mathrm{~b}$ : The more negative the attitudes toward the company, the greater the consumer negative responses toward the company.

Concluding, we investigate the effects of perceived CSI incidences that violate the ethics of community and autonomy, which are understudied areas of CSR research. Drawing upon the intuitionist framework for moral emotion (e.g., Haidt, 2012), we integrate these predictions with evaluative reactions to provide a more complete and comprehensive approach to the study of consumer response to CSI, that has not been systematically examined before. We further develop and test boundary conditions governing how moral emotions and evaluations mediate the effects of perceived CSI actions on responses that harm the corporation. Four social cognitions are used to capture these contingencies (see Figure 1).

\subsection{Hypotheses on conditional indirect effects}

When moral emotions mediate the impact of perceived CSI on consumer responses toward the company, and such mediation is regulated by individual difference variables, we term this, the conditional indirect effect of corporate irresponsible practices on consumer responses, with moral emotions as mediators and individual difference variables as moderators. For instance, as shown in Figure 1, when we combine $\mathrm{H} 1 \mathrm{a}$ and $\mathrm{H} 5 \mathrm{a}$, this demonstrates the conditional indirect effect of corporate community transgressions (or unethical business practices) on reactions toward the company, with moral emotions (contempt or anger) as the mediator and moral identity as the moderator. That is, felt moral emotions mediate the impact of perceived corporate community transgressions or unethical business practices on responses toward the corporation, where the degree of felt contempt or anger is contingent on the centrality of moral identity. Similarly, $\mathrm{H} 2 \mathrm{a}-4 \mathrm{a}$ can also be combined with $\mathrm{H} 5 \mathrm{a}$ to test the conditional indirect effects of corporate irresponsible actions on responses toward the company, with moral emotions as the mediator and each of the remaining social cognitions as the moderator. Similar rationales can be made for the conditional indirect effects of corporate irresponsible actions on responses toward the company, with attitudes as the mediator and each of the four types of social cognitions as moderators, when we combine $\mathrm{H} 1 \mathrm{~b}-\mathrm{H} 4 \mathrm{~b}$ with $\mathrm{H} 5 \mathrm{~b}$ separately.

\section{3 | METHOD}

\section{1 | Research design and stimulus materials}

We conducted a between-subjects experiment with two experimental groups and one control group. Respondents in the two experimental groups first read neutral descriptions of a Norwegian offshore shipping company. Next, they read either description of how the company conducted various irresponsible actions toward the local community violating the ethics of community, or, descriptions of how the same company conducted unethical business practices that violate the ethics of autonomy. Afterward, all respondents completed the questionnaire. Respondents in the control group only read neutral descriptions of the company and then completed the questionnaire. Our experimental manipulations are shown in Appendices $\mathrm{A}-\mathrm{C}$.

The descriptions of the offshore shipping company's irresponsible actions violating the ethics of community and autonomy were developed based on real irresponsible behaviors of companies in the Norwegian offshore shipping industry. Two industry experts who were knowledgeable about corporate irresponsible actions provided detailed advice and feedback in the development of these stimuli and helped construct them. The name of the company in the conditions was fictitious.

Furthermore, we pretested the negativity of the two manipulations among 90 adult Norwegian online consumers. Respondents were randomly assigned to three conditions (two experimental conditions and one control condition) with 30 in each condition. Both manipulations of corporate community transgressions and unethical actions worked well.

\section{2 | Respondents and procedures}

We conducted an online survey among respondents from a Norwegian panel of adult citizens. Respondents were randomly 
assigned to the two experimental conditions and the control condition. The total sample size was 211: 70 in the condition of corporate community transgressions, 71 in the condition of corporate unethical business practices, and 70 in the control condition.

Our sample consisted of 111 men (53\%) and 100 women (47\%). Of the respondents, $17 \%$ were between 16 and 24 years old, $17 \%$ 25-34 years old, $15 \% 35-44$ years old, $17 \% 45-54$ years old, $20 \%$ 55-64 years old, and 14\% over 65 . Undergraduate or higher education accounted for $78 \%$ of the sample, followed by respondents with a high school education (17\%) or less (5\%). The sample is somewhat older but still relatively representative of the target population (i.e., the Norwegian population) in gender and age. It is more highly educated than the average Norwegian population, which is common for online panels.

\section{3 | Measures}

To measure the mediators, moderators, and outcome variables shown in Figure 1, we used established scales wherever possible. Measurement items, factor loadings, and reliabilities are presented in Tables 2 and 3 .

\subsection{1 | Moral emotions and attitudes}

Negative moral emotions of contempt and anger were measured with three 7-point items each, anchored with " 1 = very weak" and "7 = very strong." Respondents were asked to indicate, "Based on the information you just read, please express the degree to which you feel the following emotions." Contempt was measured by "contemptuous," "scornful," and "disdainful"; anger was measured by "angry," "mad," and "very annoyed" (Xie et al., 2015). Attitudes toward the company were measured with two evaluative bi-polar, 7-point items: "negative-positive" and "unfavorable-favorable" (Ajzen \& Fishbein, 1980; Xie et al., 2015).

\subsection{2 | Moderators}

The four moderating variables were measured by a series of multiitem Likert items on 7-point scales. For instance, moral identity was measured by five items developed by Aquino and Reed (2002). An example is "Being someone who has these characteristics is an important part of who I am." Relational and collective self-concepts were measured by five-item subscales each from the Levels of SelfConcept Scale (Johnson et al., 2006). An example item for the relational self-concept is "It is important to me that I uphold my commitments to significant people in my life" and that for the collective self-concept is "I feel great pride when my team or group does well, even if I'm not the main reason for its success." Empathic concern was measured with seven items each from a well-known scale developed by Davis and Oathout (1987). An example item for empathic concern is "When I see someone being taken advantage of, I feel kind of protective toward them."

\subsection{3 | Outcome variables}

Outcome variables under irresponsible community actions and unethical business practices were measured by a series of multiitem Likert measures on 7-point scales, adopted from established measures (Xie et al., 2015). For instance, NWOM was measured by three items, complaint was measured by five items, and two types of boycott behaviors were measured by one item each.

\section{4 | RESULTS}

We first assessed our measurement scales by conducting confirmatory factor analysis (CFA) under each condition. Then, we applied the PROCESS Model 7 (Hayes, 2013, 2018) to test the hypothesized conditional indirect effects of CSI actions on consumer responses toward the company where consumer emotional responses and attitudes were parallel mediators (Figure 1). The results of the measurement assessment under both conditions are presented below. Then, we present the results of tests of hypotheses under corporate community transgressions $(n=140$, where we include respondents from the experimental group and the control group) and the results of hypotheses testing under corporate unethical business practices ( $n=141$ including respondents from the experimental group and the control group).

\section{1 | Measurement assessment}

We ran CFAs for the measures of mediators, moderators, and outcome variables in both conditions with LISREL. The model under corporate community transgressions fit well: $\chi^{2}(d f)=1,126.51(586)$, $p=0.0$, root mean square residual (RMSEA) $=0.081$, comparative fit index $(\mathrm{CFI})=0.95$, nonnormed fit index $(\mathrm{NNFI})=0.95$, and standardized root mean square residual $(S R M R)=0.069$.

Under corporate unethical business practices, the CFA model had satisfactory fit: $\chi^{2}(d f)=1,054.61$ (586), $p=0.0$, RMSEA $=0.070$, $\mathrm{CFI}=0.94, \mathrm{NNFI}=0.94$, and $\mathrm{SRMR}=0.069$. Factor loadings and reliability of measures in both conditions are presented in Tables 2 and 3.

As shown in Tables 2 and 3, all constructs have reliabilities above 0.78 , which are satisfactory (Nunnally, 1978). Convergent validity is established by checking whether the CFA model fits well and factor loadings are high. CFA models under both conditions fit well. Under corporate community transgressions, most factor loadings are high and significant, except for the two reverse coded items of moral identity which show lower but significant factor loadings (0.34 and 0.36), as shown in Table 2. We decided to keep these two items to use the original scale and avoid self-serving capitalization on chance in tests of hypotheses Similarly, under corporate unethical actions, most factor loadings are equal or higher than 0.60 , except for one item of collective self-concept (0.56), and two reversed items of moral identity (0.39 and 0.46), as shown in Table 3. We decided to keep these three 
TABLE 2 Measures, item loadings, and reliability under corporate community transgressions

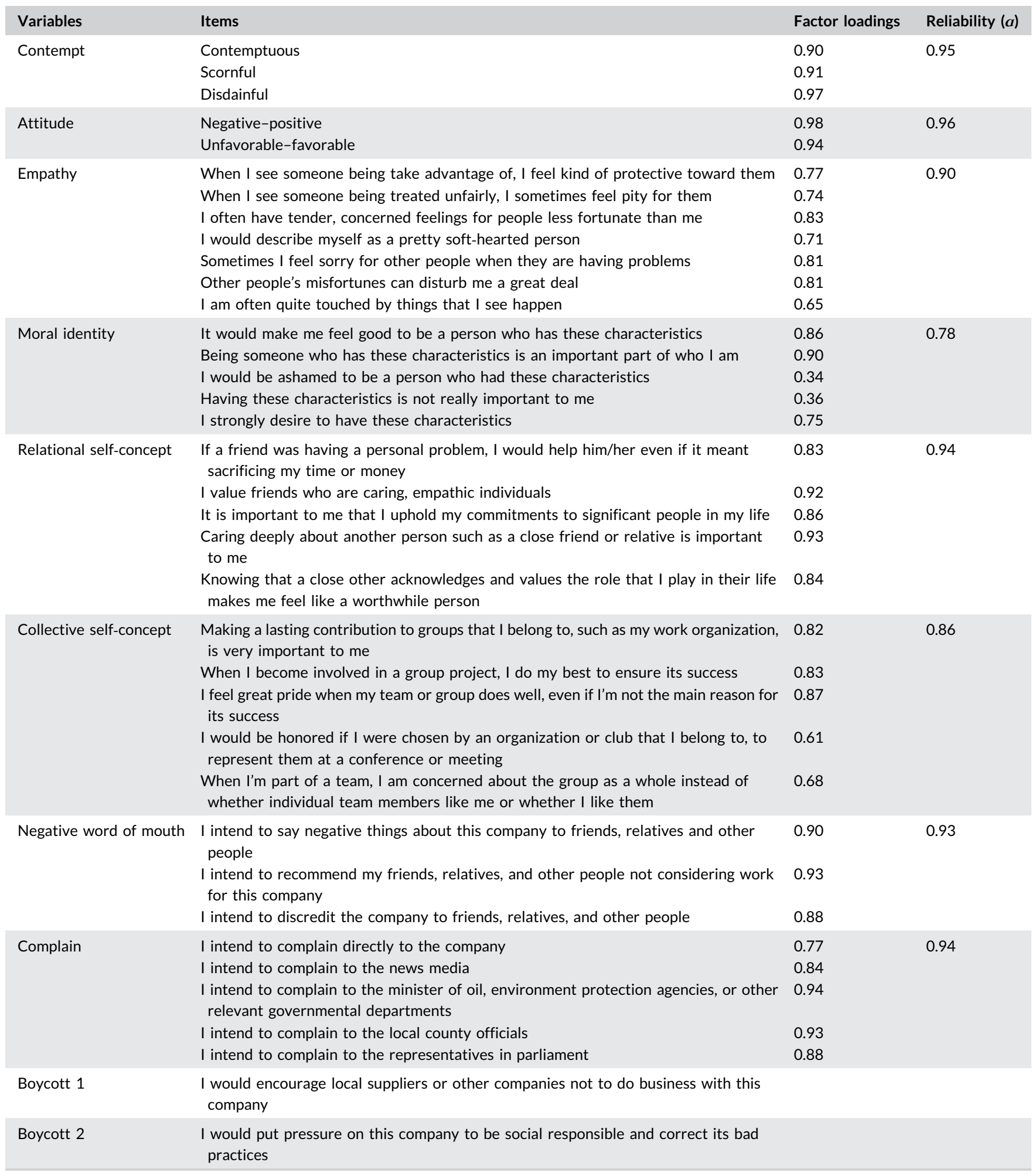

items to use the original scales of collective self-concept and moral identity.

Discriminant validity is achieved if the correlations between factors are $<1.00$ by amount greater than two standard errors. As shown in Appendices D1 and D2, discriminant validity was achieved for all constructs under both conditions.

\subsection{Corporate community transgressions consumer negative responses}

Next, we tested the hypothesized conceptual model in Figure 1. We first present results under corporate community transgressions, then the results under corporate unethical business practices. As shown in 
TABLE 3 Measures, item loadings, and reliability under corporate unethical actions

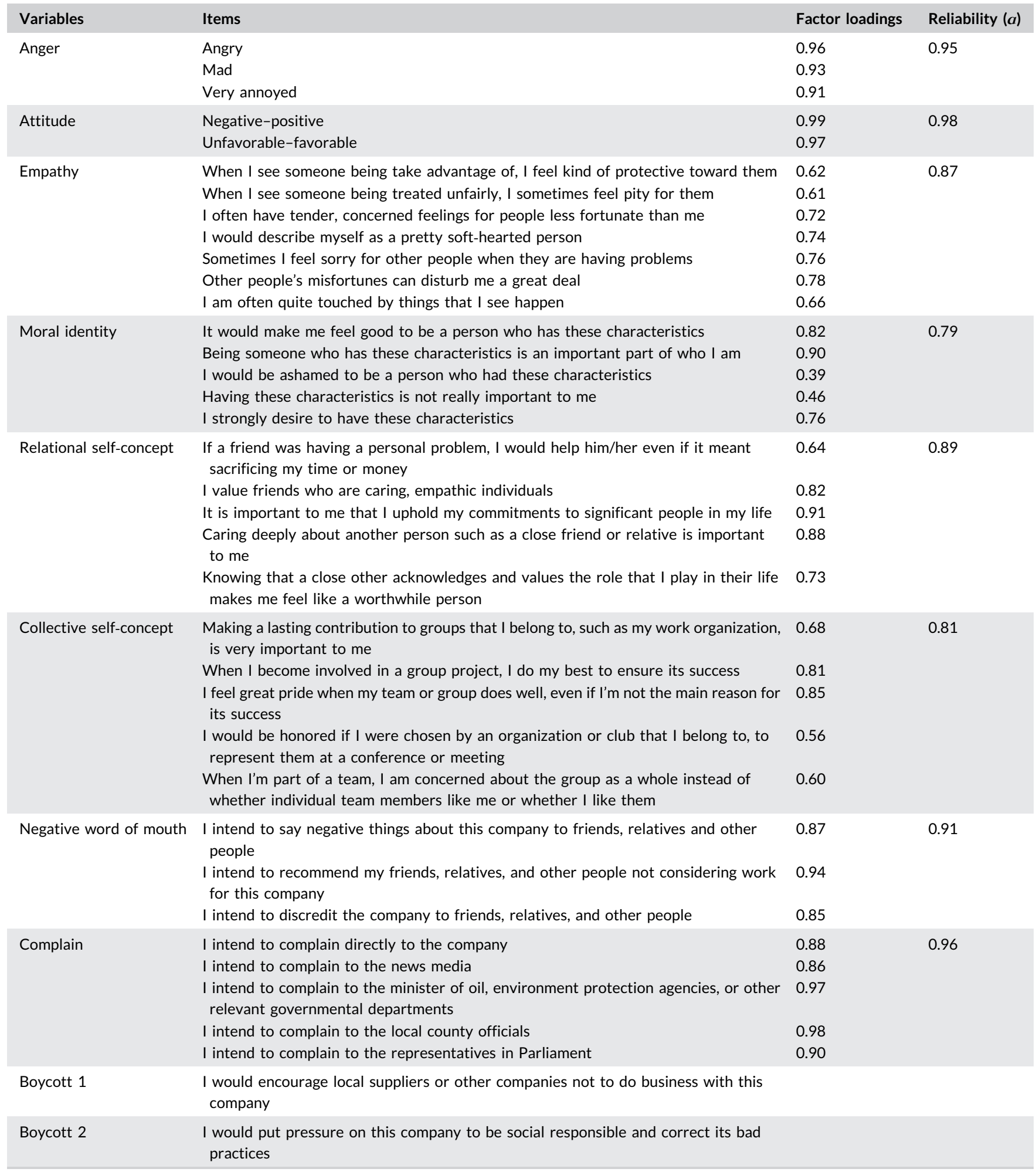

Figure 1, corporate community transgressions (i.e., violation of one's duty or obligation to the community the company functions in) evoke the negative moral emotion of contempt and negative attitudes, which, in turn, lead to such negative responses toward the company as NWOM, complaining, and boycotting. Importantly, the degree to which people experience negative emotional and evaluative reactions is regulated by four types of social cognitions. Below we first present results of the moderating effects of those four social cognitions on elicitation of contempt and negative attitudes, after being exposed to corporate community transgressions. Then, we present results of the direct effects of contempt and attitudes on negative responses toward the company. Finally, we examine whether the conditional 
indirect effect of corporate transgression on negative responses is satisfied when negative moral emotion or attitude is the mediator and each of the four social cognitions is a moderator.

\subsubsection{The moderating effects of social cognitions}

Our results show that all four types of social cognitions significantly moderate emotional and evaluative responses to perceived corporate community transgressions, as shown in Table $4 a$ and b. First, the centrality of one's moral identity influences significantly the intensity of contempt one feels when becoming aware of corporate community transgressions $(b=0.29, t=3.17)$, as shown in Table $4 a$. That is, people with more versus less central moral identities are more likely to experience more intense contempt upon the perception of corporate community transgressions. Therefore, $\mathrm{H} 1 \mathrm{a}$ is supported. Similarly, the centrality of moral identity has also a significant moderating effect on attitudes induced by perception corporate irresponsible community actions $(b=-0.57, t=-7.27)$, as shown in Table $4 \mathrm{~b}$. Thus, $\mathrm{H} 1 \mathrm{~b}$ is also supported. Together, the results show that people with more versus less central moral identities are more susceptible to experiencing negative moral emotions and negative attitudes, after being exposed to corporate actions that violate community ethics, as hypothesized.

Second, our results show that affective empathy moderates significantly the extent to which people experience contempt and negative attitudes. For instance, the more people feel concern about others' misfortunes and suffering (i.e., empathic concern), the stronger felt contempt $(b=0.42, t=4.43)$ and negative attitudes ( $b=-0.51, t=-5.68)$, upon exposure to irresponsible community practices. So, $\mathrm{H} 2 \mathrm{a}$ and $\mathrm{H} 2 \mathrm{~b}$ are also supported.

Finally, social-based self-images (i.e., the relational self-concept and collective self-concept) also influence emotional and evaluative reactions to perceived bad corporate community practices. As shown in Table $4 a$ and $b$, the relational self-concept interacts significantly with corporate community transgressions to influence both felt contempt $(b=0.11, t=2.21)$ and negative attitudes $\left(\beta_{13}=-0.31\right.$, $t=-7.80$ ), thus supporting $\mathrm{H} 3 \mathrm{a}$ and $\mathrm{H} 3 \mathrm{~b}$. That is, the stronger people hold relational self-concepts (i.e., the more they are concerned about their relationships with specific others), the stronger they reacted negatively in both emotional and evaluative ways toward corporate community transgressions. Moreover, significant interaction effects occurred between the collective self-concept and corporate community transgressions on both felt contempt $(b=0.15, t=2.90)$ and negative attitudes $(b=-0.34, t=-7.74)$. Thus, $\mathrm{H} 4 \mathrm{a}$ and $\mathrm{H} 4 \mathrm{~b}$ are also supported. These results indicate that the stronger people hold collective self-concepts (i.e., the more important they consider their memberships within their groups, their local communities), the stronger they react negatively in both emotional and evaluative ways toward corporate community transgressions.

To sum up, moral identity, emphatic concern, and relational and collective self-concepts all significantly regulated the degree to which the public experienced contempt and negative attitudes when exposed to corporate community transgressions; thus $\mathrm{H} 1 \mathrm{a}-\mathrm{H} 4 \mathrm{a}$ and $\mathrm{H} 1 \mathrm{~b}-\mathrm{H} 4 \mathrm{~b}$ were all supported. Next, we look at how such negative emotional and evaluative reactions influence negative responses toward the company.

\subsection{2 | Effects of contempt and attitudes on consumer negative responses}

As shown in Table 4c, felt contempt has significant effects on negative responses toward the company. The stronger the felt contempt, the more people feel a need to spread NWOM $(b=0.41, t=5.40)$, engage in complaint behaviors $(b=0.35, t=4.09)$, boycott the company by encouraging other companies not to do business with the company ( $b=0.46, t=4.27$ ), and put pressure on the company to correct its bad practices ( $b=0.46, t=4.13$ ). Therefore, $\mathrm{H} 5 \mathrm{a}$ is fully supported under the corporate community transgressions.

The results in Table 4c also show that attitudes only significantly influence NWOM ( $b=-0.17, t=-2.23)$ and one type of boycott behavior, pressuring the company to correct its bad practices $(b=-0.25, t=-2.25)$. Attitudes did not have significant direct effects on consumer complaining and the second type of boycott behavior.

Next, for diagnostic purposes, we examine the correlations among contempt, attitudes, and the four outcome variables, as shown in Table D1. The results show that attitudes have moderately high correlations with all four outcome variables, although those correlations are slightly lower than those between contempt and the outcome variables. However, the correlation between contempt and attitudes is 0.66 , which is higher than the correlations between attitudes and the four outcome variables. This suggests that the nonsignificant effects of attitudes on two of the four outcome variables could be due to multicollinearity and not necessarily an absence of true effects.

\subsection{3 | Conditional indirect effects}

Finally, we tested whether the conditional indirect effects of perceived corporate community transgressions on negative responses of consumers toward the company occur with contempt and attitudes as mediators, conditional on each of the four social cognitions as moderators. For instance, when we combine $\mathrm{H} 1 \mathrm{a}$ and $\mathrm{H} 5 \mathrm{a}$, we test the conditional indirect effect on the dependent variables with contempt as the mediator and moral identity as the moderator. The results show that such a conditional indirect effect indeed exists (see Table 4a and c). That is, the centrality of moral identity regulates the extent to which people experience contempt upon the perception of corporate community irresponsibility; felt contempt then further significantly impacts NWOM, consumer complaining, and boycotting. Similarly, when we combine $\mathrm{H} 2 \mathrm{a}-\mathrm{H} 4 \mathrm{a}$ with $\mathrm{H} 5 \mathrm{a}$, respectively, we test the conditional indirect effects of perceived corporate community transgressions on negative responses, where contempt functions as the mediator and the remaining social cognitions are the moderators. The results show that such conditional indirect effects occur for the relational self-concept, collective self-concept, perspective taking, and empathic concern. 
TABLE 4 Results under corporate community transgressions

\begin{tabular}{|c|c|c|c|c|}
\hline \multirow[b]{2}{*}{ Mediator (contempt) } & \multicolumn{2}{|c|}{ Moral identity } & \multicolumn{2}{|c|}{ Empathy } \\
\hline & $b$ & $t$ & $b$ & $t$ \\
\hline$X:$ manipulation $\beta_{11}$ & 1.05 & $9.25^{* * *}$ & 1.06 & $9.99^{* * *}$ \\
\hline$W:$ moderator $\beta_{12}$ & 0.09 & 0.71 & 0.13 & 1.22 \\
\hline$X \times W$ : interaction $\beta_{13}$ & 0.29 & $3.17^{* *}$ & 0.42 & $4.43^{* * *}$ \\
\hline Gender & 0.08 & 0.31 & 0.06 & 0.27 \\
\hline Age & 0.00 & 0.40 & 0.00 & -0.01 \\
\hline \multirow[t]{2}{*}{$R^{2}$} & \multicolumn{2}{|l|}{0.40} & \multicolumn{2}{|l|}{0.45} \\
\hline & \multicolumn{2}{|c|}{ Relational self-concept } & \multicolumn{2}{|c|}{ Collective self-concept } \\
\hline Mediator (contempt) & $b$ & $t$ & $b$ & $t$ \\
\hline $\mathrm{X}$ : manipulation $\beta_{11}$ & 1.06 & $8.61^{* * *}$ & 1.08 & $9.01^{* * *}$ \\
\hline W: moderator $\beta_{12}$ & 0.03 & 0.22 & 0.00 & -0.01 \\
\hline$X \times W$ : interaction $\beta_{13}$ & 0.11 & $2.21^{*}$ & 0.15 & $2.90^{* *}$ \\
\hline Gender & 0.12 & 0.49 & 0.13 & 0.52 \\
\hline Age & 0.00 & 0.58 & 0.01 & 0.70 \\
\hline$R^{2}$ & 0.38 & & 0.39 & \\
\hline \multicolumn{5}{|c|}{ (b) Mediator variable models when attitudes function as the mediator: $M=\beta_{10}+\beta_{11} X+\beta_{12} W+\beta_{13}(X \times W)+\varepsilon_{1}$} \\
\hline \multirow[b]{2}{*}{ Mediator (attitudes) } & \multicolumn{2}{|c|}{ Moral identity } & \multicolumn{2}{|c|}{ Empathy } \\
\hline & $b$ & $t$ & $b$ & $t$ \\
\hline$X:$ manipulation $\beta_{11}$ & -0.99 & $-10.05^{* * *}$ & -0.81 & $-7.98^{* * *}$ \\
\hline W: moderator $\beta_{12}$ & -0.19 & -1.79 & 0.21 & $2.00^{*}$ \\
\hline$X \times W$ : interaction $\beta_{13}$ & -0.57 & $-7.27^{* * *}$ & -0.51 & $-5.68^{* * *}$ \\
\hline Gender & -0.17 & -0.77 & -0.46 & $-1.98^{*}$ \\
\hline Age & 0.00 & 0.58 & 0.00 & -0.13 \\
\hline \multirow[t]{2}{*}{$R^{2}$} & \multicolumn{2}{|l|}{0.48} & \multicolumn{2}{|l|}{0.40} \\
\hline & \multicolumn{2}{|c|}{ Relational self-concept } & \multicolumn{2}{|c|}{ Collective self-concept } \\
\hline Mediator (attitude) & $b$ & & $b$ & $t$ \\
\hline$X:$ manipulation $\beta_{11}$ & -1.09 & $-10.67^{* * *}$ & -1.07 & $-10.58^{* * *}$ \\
\hline W: moderator $\beta_{12}$ & 0.05 & 0.52 & 0.10 & 0.66 \\
\hline$X \times W$ : interaction $\beta_{13}$ & -0.31 & $-7.80^{* * *}$ & -0.34 & $-7.74^{* * *}$ \\
\hline Gender & -0.27 & -1.29 & -0.27 & -1.32 \\
\hline Age & 0.00 & 0.02 & 0.00 & -0.30 \\
\hline$R^{2}$ & 0.50 & & 0.49 & \\
\hline
\end{tabular}

(c) Outcome variable models: $Y=\beta_{20}+\beta_{21} X+\beta_{22} M_{1}+\beta_{23} M_{2}+\varepsilon_{2}$

\begin{tabular}{|c|c|c|c|c|c|c|c|c|}
\hline \multirow[b]{2}{*}{ Outcome variables $(Y)$} & \multicolumn{2}{|c|}{ Negative word of mouth } & \multicolumn{2}{|c|}{ Complaint behaviors } & \multicolumn{2}{|c|}{ Boycott behavior 1} & \multicolumn{2}{|c|}{ Boycott behavior 2} \\
\hline & $b$ & $t$ & $b$ & $t$ & $b$ & $t$ & $b$ & $t$ \\
\hline$X:$ manipulation & 0.29 & $2.78^{* *}$ & 0.11 & 0.95 & -0.14 & -0.98 & -0.19 & -1.24 \\
\hline M1: Contempt & 0.41 & $5.40^{* * *}$ & 0.35 & $4.09^{* * *}$ & 0.46 & $4.27^{* * *}$ & 0.46 & $4.13^{* * *}$ \\
\hline M2: Attitude & -0.17 & $-2.23^{*}$ & -0.13 & -1.47 & -0.21 & -1.94 & -0.25 & $-2.25^{*}$ \\
\hline Gender & 0.05 & 0.27 & 0.19 & 0.85 & -0.15 & -0.56 & -0.10 & -0.36 \\
\hline Age & 0.00 & 0.60 & 0.01 & 0.98 & -0.01 & -0.69 & 0.00 & 0.00 \\
\hline$R^{2}$ & 0.54 & & 0.34 & & 0.28 & & 0.29 & \\
\hline
\end{tabular}

Note. M: mediator; W: moderator; $X$ : manipulation.

${ }^{*} p<0.05$.

${ }^{* *} p<0.01$.

${ }^{* * *} p<0.001$. 
Furthermore, given the significant interactions between consumer social cognitions and corporate community transgressions on felt contempt, we probed for indirect effects of these corporate actions on negative responses by estimating conditional indirect effects at three values of each moderator variable: the mean (0), 1 standard deviation above the mean $(+1 S D)$, and 1 standard deviation below the mean $(-1 S D)$, by use of bootstrapping. As shown in Table E1, our results reveal that all conditional indirect effects for the four moderators were positive and significantly different from zero at $\alpha=0.05$, given the absence of zero from each bootstrap 95\% confidence interval $(95 \% \mathrm{Cl})$. Thus the indirect effect of corporate community transgressions on consumer negative responses, via contempt, is greater when moral identity is more central rather than less central, and when the relational self-concept and collective self-concept are strong rather than weak, and when perspective-taking and empathic concern are high rather than low.

Similarly, when we combine $\mathrm{H} 1 \mathrm{~b}-\mathrm{H} 4 \mathrm{~b}$ with $\mathrm{H} 5 \mathrm{~b}$, we can also test whether the conditional indirect effects of corporate community transgressions on responses occur with attitudes as the mediator and each type of social cognition as the moderator. Our results show that these conditional indirect effects only exist for NWOM and boycotting the company, as means to pressure the company to correct its bad practices, but not the other outcomes, as shown in Table E1. As discussed earlier, these latter results could be caused by multicollinearity.

\section{3 | Corporate unethical business practices and consumer negative responses}

Next, we report the results of hypotheses testing under corporate unethical business practices (i.e., violation of the autonomy, dignity, and freedom of people). As shown in Figure 1, perceived corporate unethical actions interact with each of the four individual difference variables to elicit anger and attitudes, which further impact consumer negative behavioral responses toward the company.

\subsection{1 | The moderating effects of social cognitions}

The results show that the four individual difference variables moderate differently the intensity of consumer negative attitudes and felt negative moral emotions, upon the perception of corporate ethical transgressions, as shown in Table $5 \mathrm{a}$ and $\mathrm{b}$.

The centrality of one's moral identity interacts significantly with perceived corporate unethical actions to affect attitudes $(b=-0.30$, $t=-2.77$ ) one feels when becoming aware of corporate unethical business practices. That is, those people with more versus less central moral identities are more susceptible to have negative attitudes after being exposed to corporate unethical actions, supporting $\mathrm{H} 1 \mathrm{~b}$. But $\mathrm{H} 1 \mathrm{a}$ does not receive support although the interaction effect on anger approaches significance $(b=0.22, t=1.85)$.

Second, consumers' affective empathy also moderated significantly the extent to which people experience negative attitudes and feel CAD emotions. As shown in Table $5 a$ and $b$, the more consumers feel concerned about others' misfortunes and suffering, caused by corporate unethical actions, the stronger their felt righteous anger $(b=0.37, t=3.07)$ and more negative their attitudes $(b=-0.26$, $t=-2.38$ ), upon exposure to corporate ethical transgressions. So, $\mathrm{H} 2 \mathrm{a}$ and $\mathrm{H} 2 \mathrm{~b}$ are supported.

Third, the relational self-concept and collective self-concept influence consumer emotional and evaluative reactions to perceived corporate unethical practices. For instance, relational self-concept interacts significantly with corporate unethical actions to influence negative attitudes $(b=-0.30, t=-2.47)$, but not felt anger, thus supporting $\mathrm{H} 3 \mathrm{a}$, but not $\mathrm{H} 3 \mathrm{~b}$. This indicates that the stronger consumers hold a relational self-concept, the stronger they react negatively in evaluative ways toward corporate unethical actions. Significant interaction effects also occurred between the collective self-concept and corporate ethical transgressions on felt anger ( $b=0.28, t=2.16$ ), but not on negative attitudes, although the interaction is approaches significance $(b=-0.20, t=-1.67)$. These results indicate that the stronger consumers' collective self-concepts, the stronger their felt anger toward corporate unethical actions. Therefore, $\mathrm{H} 4 \mathrm{~b}$ received support; but $\mathrm{H} 4 \mathrm{a}$ was not supported.

\subsection{2 | Direct effects of anger and attitudes on consumer negative responses}

As shown in Table $5 c$, the consumer felt anger had significant effects on all outcome variables. That is, the stronger the felt anger, the more likely that consumers will spread NWOM $(b=0.32, t=4.11)$, engage in complaint behaviors $(b=0.23, t=2.94)$, boycott the company by encouraging other companies not to do business with the company ( $b=0.22, t=2.27$ ), and put pressure on the company to correct its bad practices ( $b=0.25, t=2.53$ ).

Consumer negative attitudes had also a significant impact on NWOM ( $b=-0.28, t=-3.33)$; however, attitudes did not have significant effects on consumer complaining and boycotting. Therefore, $\mathrm{H} 5 \mathrm{a}$ is fully supported. However, $\mathrm{H} 5 \mathrm{~b}$ received only partial support.

Furthermore, we examine correlations among felt anger, attitudes, and the four outcome variables, as shown in Table D2. The results show that attitudes have a high correlation with NWOM and moderate correlations with the other three outcome variables, although those correlations are slightly lower than those between felt anger and the outcome variables. However, the correlation between felt anger and attitudes is -0.65 . This indicates that multicollinearity is a possible cause of the nonsignificant effects of attitudes on three of the four outcome variables. The results in Table D2 also indicate that the negative emotion of anger plays a somewhat more important role than attitudes in influencing consumer negative responses toward the company.

\subsection{3 | Conditional indirect effects}

Finally, we checked whether the conditional indirect effects of corporate unethical business practices on consumer responses 
TABLE 5 Results under corporate unethical business practices

\begin{tabular}{|c|c|c|c|c|c|c|c|c|}
\hline & & \multicolumn{3}{|c|}{ Moral identity } & & \multicolumn{3}{|l|}{ Empathy } \\
\hline \multicolumn{2}{|l|}{ Mediator: Anger (W) } & \multicolumn{2}{|l|}{$b$} & \multicolumn{2}{|l|}{$t$} & \multicolumn{2}{|l|}{$b$} & $t$ \\
\hline $\mathrm{X}$ : manipulation $\beta_{11}$ & & \multicolumn{2}{|l|}{1.18} & \multicolumn{2}{|l|}{$9.62^{* * *}$} & \multicolumn{2}{|l|}{1.18} & $9.88^{* * *}$ \\
\hline$W:$ moderator $\beta_{12}$ & & \multicolumn{2}{|l|}{-0.02} & \multicolumn{2}{|l|}{-0.19} & \multicolumn{2}{|l|}{-0.03} & -0.25 \\
\hline$X \times W$ : interaction $\beta_{13}$ & & \multicolumn{2}{|l|}{0.22} & \multicolumn{2}{|l|}{1.85} & \multicolumn{2}{|l|}{0.37} & $3.07^{* *}$ \\
\hline Gender & & \multicolumn{2}{|l|}{0.54} & \multicolumn{2}{|l|}{$2.15^{*}$} & \multicolumn{2}{|l|}{0.57} & $2.28^{*}$ \\
\hline Age & & \multicolumn{2}{|l|}{0.01} & \multicolumn{2}{|l|}{0.84} & \multicolumn{2}{|l|}{0.01} & 0.97 \\
\hline \multirow[t]{2}{*}{$R^{2}$} & & \multicolumn{2}{|l|}{0.43} & & & \multicolumn{2}{|l|}{0.46} & \\
\hline & & Relationa & ncept & & & Collective & oncept & \\
\hline Mediator: Anger (W) & & $b$ & & $t$ & & $b$ & & $t$ \\
\hline$X:$ manipulation $\beta_{11}$ & & 1.18 & & $9.61^{* * *}$ & & 1.18 & & $9.77^{* * *}$ \\
\hline W: moderator $\beta_{12}$ & & -0.01 & & -0.04 & & -0.11 & & -0.86 \\
\hline$X \times W$ : interaction $\beta_{13}$ & & 0.20 & & 1.46 & & 0.28 & & $2.16^{*}$ \\
\hline Gender & & 0.53 & & $2.07^{*}$ & & 0.54 & & $2.19^{*}$ \\
\hline Age & & 0.01 & & 0.88 & & 0.01 & & 1.19 \\
\hline$R^{2}$ & & 0.43 & & & & 0.44 & & \\
\hline Mediator variable mode & when at & unction as & liator: & $\beta_{10}+\beta_{11} X+\beta_{1}$ & ${ }_{13}(X \times W)$ & & & \\
\hline & & Moral & & & & Empathy & & \\
\hline Mediator: Attitudes (W) & & $b$ & & $t$ & & $b$ & & $t$ \\
\hline$X:$ manipulation $\beta_{11}$ & & -1.26 & & $-11.50^{* * *}$ & & -1.24 & & $-11.39^{* * *}$ \\
\hline$W:$ moderator $\beta_{12}$ & & -0.12 & & -1.05 & & 0.22 & & 1.87 \\
\hline$X \times W$ : interaction $\beta_{13}$ & & -0.30 & & $-2.77^{* *}$ & & -0.26 & & $-2.38^{*}$ \\
\hline Gender & & -0.24 & & -1.06 & & -0.43 & & -1.88 \\
\hline Age & & 0.00 & & -0.60 & & -0.01 & & -1.41 \\
\hline$R^{2}$ & & 0.51 & & & & 0.52 & & \\
\hline & & Relational & cept & & & Collective & oncept & \\
\hline Mediator: Attitudes (W) & & $b$ & & $t$ & & $b$ & & $t$ \\
\hline$X:$ manipulation $\beta_{11}$ & & -1.25 & & $-11.32^{* * *}$ & & -1.25 & & $-11.25^{* * *}$ \\
\hline W: moderator $\beta_{12}$ & & -0.02 & & -0.17 & & 0.11 & & 0.91 \\
\hline$X \times W$ : interaction $\beta_{13}$ & & -0.30 & & $-2.47^{* *}$ & & -0.20 & & -1.67 \\
\hline Gender & & -0.27 & & -1.17 & & -0.31 & & -1.38 \\
\hline Age & & -0.01 & & -0.77 & & -0.01 & & -1.22 \\
\hline$R^{2}$ & & 0.51 & & & & 0.50 & & \\
\hline (c) Outcome variable mc & Is: $Y=\beta$ & $+\beta_{22} M_{1}+\rho$ & & & & & & \\
\hline & Negati & of mouth & Com! & it behaviors & Boycot & havior 1 & Boyco & ehavior 2 \\
\hline Outcome variables $(Y)$ & $b$ & $t$ & $b$ & $t$ & $b$ & $t$ & $b$ & $t$ \\
\hline$X:$ manipulation & 0.52 & $3.31^{* * *}$ & 0.24 & 1.53 & 0.43 & $2.20^{*}$ & 0.06 & 0.69 \\
\hline M: Anger & 0.32 & $4.11^{* * *}$ & 0.23 & $2.94^{* *}$ & 0.22 & $2.27^{*}$ & 0.25 & $2.53^{*}$ \\
\hline M: Attitude & -0.28 & $-3.33^{* *}$ & 0.09 & 0.99 & -0.09 & -0.84 & -0.07 & -0.66 \\
\hline Gender & -0.04 & -0.21 & 0.06 & 0.29 & 0.03 & 0.10 & 0.25 & 0.92 \\
\hline Age & -0.01 & -0.98 & 0.00 & 0.69 & 0.00 & -0.09 & 0.00 & 0.19 \\
\hline$R^{2}$ & 0.57 & & 0.15 & & 0.25 & & 0.14 & \\
\hline
\end{tabular}

Note. $\mathrm{M}$ : mediator; $\mathrm{W}$ : moderator; $X:$ manipulation .

${ }^{*} p<0.05$.

${ }^{* *} p<0.01$.

${ }^{* * *} p<0.001$ 
toward the company occur with felt anger and attitudes as mediators, conditional on each of the social cognitions as moderators. For instance, when we combine $\mathrm{H} 2 \mathrm{a}$ and $\mathrm{H} 5 \mathrm{a}$, we test the conditional indirect effect with felt anger as the mediator and empathy as the moderator. The results show that this conditional indirect effect indeed exists (see Table $5 a$ and c). That is, the strength of empathetic concern regulates the extent to which consumers experience anger upon the perception of corporate unethical actions; felt anger further had a significant impact on NWOM, complaining, and boycotting.

Furthermore, we estimated the conditional indirect effects at three values of the moderator variable (empathy): the mean (0), 1 standard deviation above the mean $(+1 S D)$, and 1 standard deviation below $(-1 S D)$, along with bootstrapping. The results in Table E2 show that, for NWOM, the conditional indirect effects are positive and different from zero at $\alpha=0.05$, given the absence of zero from the $95 \% \mathrm{Cls}$. Thus the indirect effects of perceived corporate unethical actions on consumer NWOM via felt anger is greater when empathy is stronger rather than weaker. Similar results occurred for the other consumer negative responses, consumer complaining and boycotting.

Similarly, when we combine $\mathrm{H} 4 \mathrm{a}$ with $\mathrm{H} 5 \mathrm{a}$, we test the conditional indirect effects of corporate unethical actions on consumer negative responses, where anger functions as the mediator, and the collective self-concept functions as the moderator. The results in Appendix $E$ show that the conditional indirect effects occur also for the collective self-concept. That is, the indirect effect of perceived corporate unethical actions on consumer responses, via anger, is greater when collective self-concept are strong rather than weak.

Moreover, when we combine $\mathrm{H} 1 \mathrm{~b}-\mathrm{H} 3 \mathrm{~b}$ with $\mathrm{H} 5 \mathrm{~b}$, we also test whether the conditional indirect effects of corporate unethical actions on consumer responses occur with attitudes as the mediator and each of the three social cognitions as moderators (i.e., moral identity, empathy, and relational self-concept). Our results showed that conditional indirect effects only exist for NWOM.

\section{5 | CONCLUSIONS}

\subsection{Discussion of the findings}

Our proposed model (Figure 1) received strong support in most cases under corporate community irresponsibility and unethical business practices. For instance, under corporate community transgressions, contempt mediated the impact of corporate irresponsible actions on all four outcome variables (i.e., NWOM, complaint, and boycott 1 and 2); moreover, the experience of felt contempt was conditioned by all four types of social cognitions. Therefore, the proposed mediating role of emotional processes, with contingencies by social cognitions, received full support. For attitudes, although its elicitation was also regulated by all four types of social cognitions, only direct impacts on NWOM and boycott behavior 2 resulted. So, the proposed contingent mediating role of attitudes only received partial support. However, it should be noted that, because attitudes had moderately high correlations with all outcome variables, yet an even higher correlation with its comediator, contempt, the mixed findings here with attitudes could be an artifact of multicollinearity.

Similarly, under corporate unethical business practices, anger mediated the impact of CSI actions on all four outcome variables; moreover, the intensity of felt righteous anger was conditioned by two of the four types of social cognitions (empathy and collective self-concept). For attitudes, although its elicitation was also regulated by three of the four types of social cognitions (moral identity, empathy, and relational self-concept), only a direct impact on NWOM resulted. Thus, the proposed contingent mediating role of anger received support in most cases, but the proposed contingent mediating role of attitudes only received partial support. The mixed findings with attitudes could also be an artifact of multicollinearity between attitudes and felt anger. In total, emotions are more salient and effective than attitudes in moving people to decide to take actions against corporations, when corporations act badly. Therefore, our proposed model received strong support under both corporate community transgressions and corporate unethical business practices.

Our findings also showed that both negative moral emotions and attitudes had direct impacts on intentions to engage in acts that hurt the company, but the importance of each type of reactions differed. For instance, under corporate community transgressions, felt contempt had significant effects on all four outcome variables; attitudes had significant effects only on NWOM and boycott behavior 2. An inspection of correlations in Table D1 shows that both contempt and attitudes have moderately high correlations with the four outcome variables; however, correlations between contempt and outcome variables were somewhat higher than those between attitudes and the outcome variables. This suggests perhaps that both emotional and evaluative processes are important in determining consumer negative responses toward the company, but negative moral emotion play a somewhat more important role than attitudes do.

\section{2 | Theoretical contributions}

Our study makes important theoretical contributions to extant research on CSR and moral decision making. First, we add to the emerging research on CSI applying an emotional approach by exploring multiple moderators of the emotional processes underlying consumer responses toward CSI incidences, which has not been done before. We further tested this model in the two understudied settings of CSI actions, namely, actions that violate either the ethics of community or autonomy (Shweder et al., 1997). We studied discrete emotions of contempt and anger under corresponding CSI actions, instead of aggregate CAD emotions studied in previous research (cf., Xie et al., 2015).

Second, our study contributes to CSR research and moral decision making by proposing a model that integrates three generic reactions people have toward corporate CSI actions: automatic emotional reactions, automatic evaluative reactions, and social cognitions. We suggest that both emotional and evaluative reactions 
mediate the effects of perceived company CSI actions on consumer responses toward the company, yet the extent to which these mediators function or not depend on social cognitions that people have. Our model builds on Dedeke's (2015) conceptual model that includes both automatic emotions and automatic cognitions. However, our model differs from his by suggesting that automatic emotional processes and evaluative processes operate independently, without necessarily interacting with each other, and both processes are further regulated by social cognitions, which Dedeke (2015) did not consider. Our model also extends the intuitionist approach on moral decision making (cf, Haidt, 2012) by adding evaluative processes to the emotional processes and by testing contingent conditions for both processes based on multiple social cognitions.

Concluding, our research adds to the CSR literature by developing a model of the psychological mechanisms underlying consumer responses toward company $\mathrm{CSI}$ actions and by deepening and broadening existing models on moral decision making (cf., Dedeke, 2015; Haidt, 2012) We explicitly answer the questions how do perceptions of corporate malfeasance induce consumers to act against companies, and under what conditions do these reactions occur.

\section{3 | Managerial implications}

Our findings have important implications for corporate managers as well. First, the findings show that people have stronger emotional reactions toward corporate wrongdoings than evaluative reactions although both are impactful. Special effort should be given to prevent the occurrence of CSI actions in the first place of course. Once such negative incidences occur, however, companies need to pay close attention to handling both negative emotional reactions and negative attitudes by the public, for they result in negative backlash damaging the corporation in a number of ways. Our results show that negative moral emotions evoked by the perception of CSI actions play a strong role in motivating people to engage in NWOM, complaining, and boycotting the company. As people usually feel a need to cope with discomfort caused by negative emotions and take protective actions accordingly, managers need to consider ways to lessen and mitigate such emotions in consumers. This might be done by developing communication programs vicariously inducing consumers to cope with their feelings and evaluations in constructive and realistic ways.

Second, our results show that social cognitions regulate the intensity of both felt emotional and evaluative reactions toward CSI incidences. This gives useful guidance for CSR managers in their market segmentation and communication practices. For instance, upon public exposure to corporate irresponsible actions, managers should identify people who are strong in moral identity, who hold sturdy relational and collective self-concepts, or who are high in empathic concern and target appropriate communication to them to lessen and minimize their subsequent negative responses toward the company.

\subsection{Limitations and future directions}

One limitation of our research is the use of scenarios to elicit emotional and evaluative reactions. Although the scenarios were developed based on actual incidents of corporate responsible and irresponsible actions toward the community done in the past and were constructed by industry experts, to increase the degree of realism of manipulations and elicit stronger emotional and evaluative reactions, it may be better to use videos of real events by actual companies in future studies. Nevertheless, because our stimuli are likely weaker and less vivid than viewing actual examples of corporate irresponsible behavior, our findings might underestimate effects.

We studied the moderating role of individual differences in elicitation of moral emotions and attitudes in our study, but there is a need to explore possible regulating mechanisms on the links between moral emotions/attitudes and behavioral responses; for future research other-regarding values and virtues might be candidates here, such as justice or conservative versus liberal orientations. Moreover, it would be promising to include situational variables (e.g., framing of CSR messages and time pressure in decision making) as moderators in future studies.

Another interesting direction for future research is to address the impact of perception of CSI actions on consumer responses toward third parties such as nonprofit organizations that are in alliance with the for-profit firms, nonprofit organizations opposing CSI actions, or nonprofit organizations in general.

Finally, to strengthen the generalizability of our conceptual model, the model could be tested in other industries than the shipping industry studied herein. Also, the study of specific stakeholders deserves consideration (e.g., Cronin, Smith, Gleim, Ramirez, \& Martinez, 2011). It would be interesting to look at whether such stakeholders as business customers, employees, or potential employees would react to CSI actions in similar ways as consumers do.

\section{ACKNOWLEDGMENT}

This study was supported by the Research Council of Norway (Grant No. 192270).

\section{ORCID}

Chunyan Xie (D) http://orcid.org/0000-0002-3049-5273

\section{REFERENCES}

Ajzen, I. (1991). The theory of planned behavior. Organizational Behavior and Human Decision Processes, 50(2), 179-211.

Ajzen, I., \& Fishbein, M. (1980). Understanding attitudes and predicting social behaviour. Englewood Cliffs, NJ: Prentice Hall.

Antonetti, P. (2016). Consumer anger: A label in search of meaning. European Journal of Marketing, 50(9/10), 1602-1628.

Antonetti, P., \& Maklan, S. (2016a). Social identification and corporate irresponsibility: A model of stakeholder punitive intentions. British journal of management, 27(3), 583-605. 
Antonetti, P., \& Maklan, S. (2016b). An extended model of moral outrage at corporate social irresponsibility. Journal of Business Ethics, 135(3), 429-444.

Antonetti, P., \& Maklan, S. (2017). Concerned protesters: From compassion to retaliation. European Journal of Marketing, 51(5/6), 983-1010.

Antonetti, P., \& Maklan, S. (2018). Identity bias in negative word of mouth following irresponsible corporate behavior: A research model and moderating effects. Journal of Business Ethics, 149(4), 1005-1023.

Aquino, K., Freeman, D., Reed, A., Lim, V. K. G., \& Felps, W. (2009). Testing a social-cognitive model of moral behavior: The interactive influence of situations and moral identity centrality. Journal of Personality and Social Psychology, 97(1), 123-141.

Aquino, K., McFerran, B., \& Laven, M. (2011). Moral identity and the experience of moral elevation in response to acts of uncommon goodness. Journal of Personality and Social Psychology, 100(4), 703-718.

Aquino, K., \& Reed, A. (2002). The self-importance of moral identity. Journal of Personality and Social Psychology, 83(6), 1423-1440.

Bagozzi, R. P., \& Warshaw, P. R. (1990). Trying to consume. Journal of consumer research, 17(2), 127-140.

Blasi, A. (2004). Moral functioning: Moral understanding and personality. In D. K. Lapsley, \& D. Narvaez (Eds.), Moral development, self, and identity (pp. 335-348). Mahwah, NJ: Erlbaum.

Brewer, M. B., \& Gardner, W. (1996). Who is this "We"? Levels of collective identity and self representations. Journal of Personality and Social Psychology, 71(1), 83-93.

Brown, T. J., \& Dacin, P. A. (1997). The company and the product: Corporate associations and consumer product responses. The Journal of Marketing, 61, 68-84.

Cronin, J. J., Smith, J. S., Gleim, M. R., Ramirez, E., \& Martinez, J. D. (2011). Green marketing strategies: An examination of stakeholders and the opportunities they present. Journal of the Academy of Marketing Science, 39(1), 158-174.

Davis, M. H., \& Oathout, H. A. (1987). Maintenance of satisfaction in romantic relationships: Empathy and relational competence. Journal of Personality and Social Psychology, 53(2), 397-410.

Dedeke, A. (2015). A cognitive-intuitionist model of moral judgment. Journal of Business Ethics, 126(3), 437-457.

Ekman, P. (1994). Antecedent events and emotion metaphors. In P. Ekman, \& R. J. Davidson (Eds.), The nature of emotion: Fundamental questions (pp. 146-149). New York: Oxford University Press.

Elsbach, K. D., \& Bhattacharya, C. B. (2001). Defining who you are by what you're not: Organizational disidentification and the National Rifle Association. Organization Science, 12(4), 393-413.

Folkes, V., \& Kamins, M. (1999). Effects of information about firms' ethical and unethical actions on consumers' attitudes. Journal of Consumer Psychology, 8(3), 243-259.

Fredrickson, B. L. (1998). What good are positive emotions? Review of General Psychology, 2(3), 300-319.

Fredrickson, B. L., \& Branigan, C. (2005). Positive emotions broaden the scope of attention and thought-action repertoires. Cognition \& Emotion, 19(3), 313-332.

Grappi, S., Romani, S., \& Bagozzi, R. P. (2013a). Consumer response to corporate irresponsible behavior: Moral emotions and virtues. Journal of Business Research, 66(10), 1814-1821.

Grappi, S., Romani, S., \& Bagozzi, R. P. (2013b). The effects of company offshoring strategies on consumer responses. Journal of the Academy of Marketing Science, 41(6), 683-704.

Haidt, J. (2012). The righteous mind: Why good people are divided by politics and religion. New York: Vintage Books, A division of Random House, Inc.

Haidt, J. (2003). The moral emotions. In R. J. Davidson, K. R. Sherer, \& H. H. Goldsmith (Eds.), Handbook of affective sciences (pp. 852-870). Oxford: Oxford University Press.
Hayes, A. F. (2013). An introduction to mediation, moderation, and conditional process analysis: A regression-based approach. New York: Guilford Press.

Hayes, A. F. (2018). An introduction to mediation, moderation, and conditional process analysis: A regression-based approach (2nd ed.). New York: Guilford Press.

Izard, C. E. (1977). Human emotions. New York: Plenum Press.

Johnson, R. E., Selenta, C., \& Lord, R. G. (2006). When organizational justice and the self-concept meet: Consequences for the organization and its members. Organizational Behavior and Human Decision Processes, 99(2), 175-201.

Judge, T. A., \& Kammeyer-Mueller, J. D. (2012). Job attitudes. Annual Review of Psychology, 63, 341-367.

Klein, J., \& Dawar, N. (2004). Corporate social responsibility and consumers' attributions and brand evaluations in a product-harm crisis. International Journal of research in Marketing, 21(3), 203-217.

Lazarus, R. S. (1991). Emotion and adaptation. New York: Oxford University Press.

Losoya, S. H., \& Eisenberg, N. (2001). Affective empathy. In J. A. Hall, \& F. J. Bernieri (Eds.), Theory and measurement (pp. 21-43). Mahwah, NJ: Erlbaum.

Markus, H. R., \& Kitayama, S. (1991). Culture and the self: Implications for cognition, emotion, and motivation. Psychological Review, 98(2), 224-253.

Miller, W. I. (1997). The anatomy of disgust. Cambridge, MA: Harvard University Press.

Mohr, L. A., \& Webb, D. J. (2005). The effects of corporate social responsibility and price on consumer responses. Journal of consumer affairs, 39(1), 121-147.

Nunnally, J. C. (1978). Psychometric theory (2nd ed.). New York: McGraw-Hill.

Peloza, J., \& Shang, J. (2011). How can corporate social responsibility activities create value for stakeholders? A systematic review. Journal of the Academy of Marketing Science, 39(1), 117-135.

Romani, S., Grappi, S., Bagozzi, R. P., \& Barone, A. M. (2013). My anger is your gain, my contempt your loss: Explaining consumer responses to corporate wrongdoing. Psychology \& Marketing, 30(12), 1029-1042.

Romani, S., Grappi, S., Zarantonello, L., \& Bagozzi, R. P. (2015). The revenge of the consumer! How brand moral violations lead to consumer anti-brand activism. Journal of Brand Management, 22(8), 658-672.

Rozin, P., Lowery, L., Imada, S., \& Haidt, J. (1999). The CAD triad hypothesis: A mapping between three moral emotions (contempt, anger, disgust) and three moral codes (community, autonomy, divinity). Journal of Personality and Social Psychology, 76(4), 574-586.

Shweder, R., Much, N., Mahapatra, M., \& Park, L. (1997). The "big three" of morality (autonomy, community, and divinity), and the "big three" explanations of suffering. In A. Brandt, \& P. Rozin (Eds.), Morality and health (pp. 119-169). New York: Routledge.

Tangney, J. P., Stuewig, J., \& Mashek, D. J. (2007). Moral emotions and moral behavior. Annual Review of Psychology, 58, 345-372.

Vaaland, T. I., Heide, M., \& Grønhaug, K. (2008). Corporate social responsibility: Investigating theory and research in the marketing context. European Journal of Marketing, 42(9/10), 927-953.

Weaver, G. R., Reynolds, S. J., \& Brown, M. E. (2014). Moral intuition: Connecting current knowledge to future organizational research and practice. Journal of Management, 40(1), 100-129.

Xie, C., Bagozzi, R. P., \& Grønhaug, K. (2015). The role of moral emotions and individual differences in consumer responses to corporate green and non-green actions. Journal of the Academy of Marketing Science, 43(3), 333-356.

Xie, C., Bagozzi, R. P., \& Grønhaug, K. (2019). The impact of corporate social responsibility on consumer brand advocacy: The role of moral 
emotions, attitudes, and individual differences. Journal of Business Research, 95, 514-530.

Chunyan Xie is a Professor of Marketing. Her areas of interests include corporate social responsibility and corporate reputation, moral emotions, consumer cocreation and prosumption behavior, and consumer materialism. She applies both quantitative methods (e.g., experiment, survey) and qualitative methods (e.g., interview and focus group discussion) and in her research.

Richard P. Bagozzi is the Dwight F. Benton Professor of Behavioral Science in Management. He does basic research into human emotions, decision making, social identity, ethics, action, neuroscience, and genetics. He also does research into multivariate statistics and its relationship to measurement, construct validity, theory, hypotheses testing, and the philosophy of science.

How to cite this article: Xie C, Bagozzi RP. Consumer responses to corporate social irresponsibility: The role of moral emotions, evaluations, and social cognitions. Psychol. Mark. 2019;36:565-586. https://doi.org/10.1002/mar.21197

\section{APPENDIX A: NARRATIVE SCENARIO OF CORPORATE COMMUNITY TRANSGRESSIONS}

Offshore Shipping ASA is a stock exchange listed company in western Norway with 1,700 employees, and that owns and operates 35 special ships within supply activities, subsea construction, seismic operations, and tow and anchor handling operations. A large part of these are currently under contract to oil- and petroleum-related companies, both in the Norwegian sector and in foreign waters. Over the last 25 years, Offshore Shipping ASA has, by Norwegian standards, gradually grown to be a large and significant player within offshore shipping.

Despite being a large and economically significant performer in Norwegian shipping, Offshore Shipping ASA has a negative reputation among public, business, and government. Among other things, the shipping company is known for secrecy in its operations and business dealings and consistently maintaining a closed external profile. Despite being located in a region with a relatively large maritime business cluster, Offshore Shipping ASA conducts few business relationships with local suppliers. Offshore Shipping ASA has consistently rejected potential partners and local businesses contracts and refuses to participate in joint activities of significance with them.

As a result of economic growth and a growing fleet of vessels, Offshore Shipping ASA several years ago felt the need to acquire a larger, modern docking facility. The dock was to be used for mobilization, maintenance, and the storage of equipment. In selecting the location, Offshore Shipping ASA considered a number of strategic, geographic, and meteorological criteria. The choice landed on a location that at that time was a very attractive and popular recreational area for the local population. The location was part of an attractive area for walking and hiking, and had some facilities for swimming and fishing, as well as being an important reserve for protected species of birds. To avoid criticism and resistance, the shipping company chose to consistently run a closed and secretive process around the building project. At an early point in the process, the area was purchased from the property owner for a significant amount. However, as the plans became public, they led to a stream of complaints, negative newspaper articles, and protests. When the building plans were nonetheless finally approved by the local municipality, where claims of financial pressure and even bribery were alleged, many felt that this was a direct consequence of Offshore Shipping ASA's ability to push through a ruling based on the company's size and economic weight at the local citizens' expense.

In addition, Offshore Shipping ASA has also repeatedly been criticized in the local press for its lack of ability in contributing to the development of idealistic local goals, clubs, and sports teams. This is despite the fact that for many years the shipping company has had very good economic results. The same line of thought became clear when Offshore Shipping ASA chose to be the only large shipping company not to join a joint research and development initiative among a number of local shipping companies, maritime industry suppliers, and the local college to improve use and sustainability of natural resources, reduce pollution, and in general practice good social policy.

\section{APPENDIX B: NARRATIVE SCENARIO OF CORPORATE UNETHICAL BUSINESS PRACTICES}

Offshore Shipping ASA is a stock exchange listed company in western Norway with 1,700 employees, and that owns and operates 35 special ships within supply activities, subsea construction, seismic operations, and tow and anchor handling operations. A large part of these are currently under contract to oil and petroleum-related companies, both in the Norwegian sector and in foreign waters. Over the last 25 years, Offshore Shipping ASA has, by Norwegian standards, gradually grown to be a large and significant player within offshore shipping.

Offshore Shipping ASA is known for its aggressive marketing program. Furthermore, in recent years the shipping company has had a special focus on expansion in international markets often at the expense of small shipping companies in these countries. In relationship to this, Offshore ASA's General Manager has stated that further growth in the company and the continued development of their solutions will specifically depend on access to new markets. However, the shipping company's international efforts have also 
been the object of criticism by governmental and watchdog agencies regarding unethical practices trade relationships.

Among other things, the press and nongovernmental and international idealistic organizations have repeatedly revealed that the shipping company has had and continues to have contracts with governments and companies that are viewed as unethical and unscrupulous due to political, social, or economics practices. This includes having business relationships with dictatorships with which the Norwegian Foreign Ministry strongly advises against doing business, as well as with countries and companies where corruption is considered a common daily affair. For Offshore Shipping ASA, such business relationships usually involve entering into contracts for the delivery of services to an oil or well-drilling company with dubious accounting, financial, and operational practices, which negatively impact local small business and existing suppliers.

Recently, Offshore Shipping ASA has also been publicly criticized for failing to perform due diligence before signing contracts where suspected ethical practices exist. At the same time, the shipping company failed to certify that their purchasing practices maintained minimum standards of ethical accounting practices and business conduct. Offshore Shipping ASA's General Manager seems unconcerned that the shipping company may enter into contracts with countries and companies that the government or international organizations consider to be unethical. Instead, the general manager publicly boasts that profit means everything for Offshore Shipping ASA. Such actions and statements have led a number of Norwegian and international help and aid organizations to express their strong condemnation of Offshore Shipping ASA, and over time to urge a boycott of the shipping company by public and private companies in Norway.

At around the same time that the conditions mentioned above were receiving the full attention of the media, a number of criticizable working and safety conditions on board many of the company's ship were revealed. Among other things, several near accidents were exposed where equipment or facilities with deficiencies were involved. Anonymous employees have later revealed that it appears as if the shipping company premeditatedly neglects maintenance procedures, and thereby prioritizes profits above the lives and health of the crews.

\section{APPENDIX C: NARRATIVE SCENARIO FOR THE CONTROL CONDITION}

Offshore Shipping ASA is a stock exchange listed shipping company that currently owns and operates around 35 special ships within the petro-maritime sector. The fleet includes a number of supply vessels, construction, and subsea operations vessels, seismic vessels, and offshore anchor handling tug vessels. A large part of these are currently under contract to oil- and petroleum-related companies, both in the Norwegian sector and in foreign waters. At the same time, individual vessels operate on shorter contracts within the socalled spot market. Since the company was established, Offshore Shipping ASA's main office has been located in western Norway. Over time, a number of foreign agent offices have also been opened. Over the last 25 years, Offshore Shipping ASA has, by Norwegian standards, gradually grown to be a large and significant player within offshore shipping.

Today, Offshore Shipping ASA employs about 1,700 people, both offshore and onshore. As for the various onshore offices, these encompass operations and management, diverse personnel and offshore support functions, as well as a separate development division. The development division has focuses on technological refinements as a step toward expanding in existing and new markets. A large proportion of the employees on Offshore ASA's ships today are Norwegian citizens. Both the wage conditions and retirement arrangements that Offshore Shipping ASA offers are considered competitive by Norwegian standards.

Like similar companies, Offshore Shipping ASA has a program for customer support and maintaining operations. The shipping company has been able to offer functional and cost-effective vessel solutions while maintaining international standards. In recent years, Offshore Shipping ASA has focused on expansion in international markets. This includes areas around Brazil and the Gulf of Mexico. Offshore Shipping ASA's General Manager has stated that further growth in the company and the continued development of their solutions will largely depend on access to new and international markets. 


\section{APPENDIX D}

TABLE D1 Correlation matrix of latent constructs in the condition of corporate community transgressions

\begin{tabular}{|c|c|c|c|c|c|c|c|c|c|c|}
\hline & Conempt & Attitude & Empathy & MI & Rela-self & Col-self & NWOM & Compl & Boycott 1 & Boycott 2 \\
\hline Contempt & 1.00 & & & & & & & & & \\
\hline Attitude & $\begin{array}{c}-0.66 \\
(0.05)\end{array}$ & 1.00 & & & & & & & & \\
\hline Empathy & $\begin{array}{c}0.03 \\
(0.09)\end{array}$ & $\begin{array}{c}0.10 \\
(0.09)\end{array}$ & 1.00 & & & & & & & \\
\hline MI & $\begin{array}{c}-0.02 \\
(0.09)\end{array}$ & $\begin{array}{c}-0.02 \\
(0.09)\end{array}$ & $\begin{array}{c}0.68 \\
(0.05)\end{array}$ & 1.00 & & & & & & \\
\hline Rela-self & $\begin{array}{c}-0.07 \\
(0.09)\end{array}$ & $\begin{array}{c}-0.02 \\
(0.09)\end{array}$ & $\begin{array}{c}0.58 \\
(0.06)\end{array}$ & $\begin{array}{c}0.72 \\
(0.05)\end{array}$ & 1.00 & & & & & \\
\hline Col-self & $\begin{array}{c}-0.06 \\
(0.09)\end{array}$ & $\begin{array}{c}-0.02 \\
(0.09)\end{array}$ & $\begin{array}{c}0.61 \\
(0.06)\end{array}$ & $\begin{array}{c}0.61 \\
(0.06)\end{array}$ & $\begin{array}{c}0.78 \\
(0.04)\end{array}$ & 1.00 & & & & \\
\hline NWOM & $\begin{array}{c}0.74 \\
(0.04)\end{array}$ & $\begin{array}{c}-0.61 \\
(0.06)\end{array}$ & $\begin{array}{c}0.14 \\
(0.09)\end{array}$ & $\begin{array}{c}0.05 \\
(0.09)\end{array}$ & $\begin{array}{c}-0.08 \\
(0.09)\end{array}$ & $\begin{array}{c}0.09 \\
(0.09)\end{array}$ & 1.00 & & & \\
\hline Boycott 1 & $\begin{array}{c}0.52 \\
(0.06)\end{array}$ & $\begin{array}{c}-0.44 \\
(0.07)\end{array}$ & $\begin{array}{c}0.22 \\
(0.08)\end{array}$ & $\begin{array}{c}0.12 \\
(0.09)\end{array}$ & $\begin{array}{c}0.06 \\
(0.09)\end{array}$ & $\begin{array}{c}0.22 \\
(0.09)\end{array}$ & $\begin{array}{c}0.70 \\
(0.05)\end{array}$ & $\begin{array}{c}0.65 \\
(0.05)\end{array}$ & 1.00 & \\
\hline Boycott 2 & $\begin{array}{c}0.52 \\
(0.06)\end{array}$ & $\begin{array}{c}-0.46 \\
(0.07)\end{array}$ & $\begin{array}{c}0.25 \\
(0.08)\end{array}$ & $\begin{array}{c}0.15 \\
(0.09)\end{array}$ & $\begin{array}{c}0.07 \\
(0.09)\end{array}$ & $\begin{array}{c}0.23 \\
(0.08)\end{array}$ & $\begin{array}{c}0.66 \\
(0.05)\end{array}$ & $\begin{array}{c}0.77 \\
(0.04)\end{array}$ & $\begin{array}{c}0.78 \\
(0.03)\end{array}$ & 1.00 \\
\hline
\end{tabular}

Note. Values within parentheses are standard errors.

Col-self: collective self-concept; Compl: complain; Empathy: empathic concern; MI: moral identity; NWOM: negative word of mouth; Perspect: perspective taking; Rela-self: relational self-concept.

TABLE D2 Correlation matrix of latent constructs under corporate unethical business practices

\begin{tabular}{|c|c|c|c|c|c|c|c|c|c|c|}
\hline & Anger & Attitude & Empathy & MI & Rela-self & Col-self & NWOM & Compl & Boycott 1 & Boycott 2 \\
\hline Anger & 1.00 & & & & & & & & & \\
\hline Attitude & $\begin{array}{c}-0.65 \\
(0.05)\end{array}$ & 1.00 & & & & & & & & \\
\hline Empathy & $\begin{array}{c}0.03 \\
(0.09)\end{array}$ & $\begin{array}{c}0.10 \\
(0.09)\end{array}$ & 1.00 & & & & & & & \\
\hline MI & $\begin{array}{c}-0.02 \\
(0.09)\end{array}$ & $\begin{array}{c}0.04 \\
(0.09)\end{array}$ & $\begin{array}{c}0.58 \\
(0.07)\end{array}$ & 1.00 & & & & & & \\
\hline Rela-self & $\begin{array}{c}0.02 \\
(0.09)\end{array}$ & $\begin{array}{c}0.06 \\
(0.09)\end{array}$ & $\begin{array}{c}0.51 \\
(0.07)\end{array}$ & $\begin{array}{c}0.66 \\
(0.06)\end{array}$ & 1.00 & & & & & \\
\hline Col-self & $\begin{array}{c}-0.01 \\
(0.09)\end{array}$ & $\begin{array}{c}0.02 \\
(0.09)\end{array}$ & $\begin{array}{c}0.51 \\
(0.08)\end{array}$ & $\begin{array}{c}0.43 \\
(0.08)\end{array}$ & $\begin{array}{c}0.67 \\
(0.06)\end{array}$ & 1.00 & & & & \\
\hline NWOM & $\begin{array}{c}0.69 \\
(0.05)\end{array}$ & $\begin{array}{c}-0.69 \\
(0.05)\end{array}$ & $\begin{array}{c}0.03 \\
(0.09)\end{array}$ & $\begin{array}{c}0.06 \\
(0.09)\end{array}$ & $\begin{array}{c}0.05 \\
(0.09)\end{array}$ & $\begin{array}{c}0.12 \\
(0.09)\end{array}$ & 1.00 & & & \\
\hline Boycott 1 & $\begin{array}{c}0.45 \\
(0.07)\end{array}$ & $\begin{array}{c}-0.42 \\
(0.07)\end{array}$ & $\begin{array}{c}0.20 \\
(0.09)\end{array}$ & $\begin{array}{c}0.06 \\
(0.09)\end{array}$ & $\begin{array}{c}0.06 \\
(0.09)\end{array}$ & $\begin{array}{c}0.11 \\
(0.09)\end{array}$ & $\begin{array}{c}0.65 \\
(0.05)\end{array}$ & $\begin{array}{c}0.57 \\
(0.06)\end{array}$ & 1.00 & \\
\hline Boycott 2 & $\begin{array}{c}0.38 \\
(0.07)\end{array}$ & $\begin{array}{c}-0.29 \\
(0.08)\end{array}$ & $\begin{array}{c}0.21 \\
(0.09)\end{array}$ & $\begin{array}{c}0.08 \\
(0.09)\end{array}$ & $\begin{array}{c}0.03 \\
(0.09)\end{array}$ & $\begin{array}{c}0.05 \\
(0.09)\end{array}$ & $\begin{array}{c}0.42 \\
(0.07)\end{array}$ & $\begin{array}{c}0.65 \\
(0.05)\end{array}$ & $\begin{array}{c}0.73 \\
(0.04)\end{array}$ & 1.00 \\
\hline
\end{tabular}

Compl: complain; Col-self: collective self-concept; MI: moral identity; NWOM: negative word of mouth; Rela-self: relational self-concept; Social-just: social justice values. 


\section{APPENDIX E}

TABLE E1 Conditional indirect effects contempt as a mediator under corporate community transgressions

\begin{tabular}{|c|c|c|c|c|c|c|c|c|}
\hline \multirow{3}{*}{$\begin{array}{l}\text { Mediator: Contempt } \\
\text { Moderators } \\
\text { Moral identity }\end{array}$} & \multicolumn{8}{|c|}{ Outcome variables } \\
\hline & \multicolumn{2}{|c|}{ Negative word of mouth } & \multicolumn{2}{|c|}{ Complaint behaviors } & \multicolumn{2}{|c|}{ Boycott behavior 1} & \multicolumn{2}{|c|}{ Boycott behavior 2} \\
\hline & Effect & $95 \% \mathrm{Cl}$ & Effect & $95 \% \mathrm{Cl}$ & Effect & $95 \% \mathrm{Cl}$ & Effect & $95 \% \mathrm{Cl}$ \\
\hline$W=0$ & 0.44 & $0.23,0.65$ & 0.37 & $0.15,0.63$ & 0.48 & $0.24,0.77$ & 0.48 & $0.19,0.83$ \\
\hline$W=+1 S D(1.05)$ & 0.56 & $0.29,0.86$ & 0.47 & $0.18,0.85$ & 0.62 & $0.30,1.02$ & 0.62 & $0.24,1.10$ \\
\hline \multicolumn{9}{|l|}{ Relational self-concept } \\
\hline$W=0$ & 0.44 & $0.23,0.65$ & 0.37 & $0.14,0.63$ & 0.48 & $0.24,0.78$ & 0.49 & $0.19,0.83$ \\
\hline$W=+1 S D(1.06)$ & 0.48 & $0.26,0.75$ & 0.41 & $0.16,0.74$ & 0.53 & $0.27,0.92$ & 0.54 & $0.21,0.98$ \\
\hline \multicolumn{9}{|l|}{ Collective self-concept } \\
\hline$W=-1 S D(-1.14)$ & 0.38 & $0.09,0.56$ & 0.32 & $0.07,0.52$ & 0.42 & $0.11,0.65$ & 0.42 & $0.10,0.69$ \\
\hline$W=0$ & 0.45 & $0.23,0.66$ & 0.38 & $0.15,0.64$ & 0.50 & $0.25,0.78$ & 0.50 & $0.19,0.83$ \\
\hline$W=+1 S D$ & 0.64 & $0.34,0.96$ & 0.54 & $0.22,0.92$ & 0.71 & $0.35,1.14$ & 0.71 & $0.28,1.22$ \\
\hline \multicolumn{2}{|l|}{ Mediator: Attitude } & \multicolumn{7}{|c|}{ Outcome variables } \\
\hline Moderators & & \multicolumn{3}{|c|}{ Negative word of mouth } & & \multicolumn{3}{|c|}{ Boycott behavior 2} \\
\hline Moral identity & & Effect & & $95 \% \mathrm{Cl}$ & & Effect & & $95 \% \mathrm{Cl}$ \\
\hline$W=-1 S D(-1.05)$ & & 0.07 & & $0.01,0.31$ & & 0.10 & & $-0.05,0.27$ \\
\hline$W=0$ & & 0.17 & & $0.03,0.44$ & & 0.25 & & $-0.08,0.47$ \\
\hline$W=+1 S D(1.05)$ & & 0.27 & & $0.05,0.59$ & & 0.40 & & $-0.11,0.76$ \\
\hline \multicolumn{9}{|l|}{ Relational self-concept } \\
\hline$W=-1 S D(-1.14)$ & & 0.13 & & $0.03,0.34$ & & 0.19 & & $-0.06,0.37$ \\
\hline$W=-1 S D(-1.17)$ & & 0.04 & & $-0.03,0.30$ & & 0.05 & & $-0.09,0.26$ \\
\hline$W=0$ & & 0.14 & & $0.02,0.43$ & & 0.21 & & $-0.08,0.41$ \\
\hline$W=+1 S D(1.17)$ & & 0.24 & & $0.05,0.59$ & & 0.36 & & $-0.11,0.71$ \\
\hline
\end{tabular}

Note. $95 \% \mathrm{Cl}$ : bootstrap 95\% confidence intervals for conditional indirect effect; Effect: conditional indirect effect; SD: standard deviation. 
TABLE E2 Conditional indirect effects contempt as mediator under corporate unethical business practices

\begin{tabular}{|c|c|c|c|c|c|c|c|c|}
\hline \multirow{2}{*}{$\begin{array}{l}\text { Mediator: Anger } \\
\text { Moderators } \\
\text { Empathic concern }\end{array}$} & \multicolumn{8}{|c|}{ Outcome variables } \\
\hline & Effect & $95 \% \mathrm{Cl}$ & Effect & $95 \% \mathrm{Cl}$ & Effect & $95 \% \mathrm{Cl}$ & Effect & $95 \% \mathrm{Cl}$ \\
\hline$W=0$ & 0.37 & $(0.16,0.62)$ & 0.28 & $0.08,0.52$ & 0.26 & $0.03,0.55$ & 0.29 & $0.03,0.60$ \\
\hline$W=+1 S D(1.00)$ & 0.49 & $(0.20,0.82)$ & 0.36 & $0.10,0.69$ & 0.34 & $0.04,0.72$ & 0.38 & $0.04,0.79$ \\
\hline$W=0$ & 0.37 & $(0.16,0.64)$ & 0.28 & $0.08,0.52$ & 0.26 & $0.03,0.54$ & 0.29 & $0.04,0.60$ \\
\hline$W=+1 S D(0.94)$ & 0.46 & $(0.19,0.77)$ & 0.34 & $0.09,0.65$ & 0.32 & $0.04,0.66$ & 0.36 & $0.04,0.74$ \\
\hline \multirow{2}{*}{$\begin{array}{l}\text { Mediator: Attitude } \\
\text { Moderators } \\
\text { Moral identity }\end{array}$} & & & & \multicolumn{5}{|c|}{ Outcome variable } \\
\hline & & & & \multicolumn{5}{|c|}{ Negative word of mouth } \\
\hline \multicolumn{9}{|l|}{ Relational self-concept } \\
\hline$W=-1 S D(-.94)$ & & & & 0.27 & & & & $0.11,0.50$ \\
\hline$W=0$ & & & & 0.35 & & & & $0.14,0.66$ \\
\hline$W=+1 S D(0.94)$ & & & & 0.43 & & & & $0.16,0.84$ \\
\hline \multicolumn{9}{|l|}{ Empathic concern } \\
\hline$W=-1 S D(-1.00)$ & & & & 0.28 & & & & $0.11,0.52$ \\
\hline$W=0$ & & & & 0.35 & & & & $0.14,0.66$ \\
\hline$W=+1 S D(1.00)$ & & & & 0.42 & & & & $0.16,0.82$ \\
\hline
\end{tabular}

Note. $95 \% \mathrm{Cl}$ : bootstrap 95\% confidence intervals for conditional indirect effect; Effect: conditional indirect effect; SD: standard deviation. 